\title{
Numerical analysis on a novel CGPFs for improve NOx conversion efficiency and particulate combustion efficiency to reduce exhaust pollutant emission
}

\author{
Yong Xie ( $\nabla$ xyong0808@163.com ) \\ Xiangtan University \\ Qingsong Zuo \\ Xiangtan University School of Mechanical Engineering \\ Qingwu Guan \\ Technique Center, Hunan Tyen Machinery Co., Ltd. \\ Kexiang Wei \\ Hunan provincial Key Laboratory of Vehicle Power and Transmission System \\ Bin Zhang \\ Xiangtan University School of Mechanical Engineering
}

\section{Research Article}

Keywords: Particulate combustion efficiency, Electric heating power, Catalytic gasoline particulate filter system, Gasoline engine, NOx conversion efficiency, Vehicle emission

Posted Date: September 10th, 2021

DOI: https://doi.org/10.21203/rs.3.rs-888878/v1

License: (c) (1) This work is licensed under a Creative Commons Attribution 4.0 International License.

Read Full License 


\title{
Numerical analysis on a novel CGPFs for improve NOx conversion efficiency and particulate combustion efficiency to reduce exhaust pollutant emission
}

\author{
Yong Xie ${ }^{\mathrm{a}}$, Qingsong Zuo ${ }^{\mathrm{a}, *}$, Qingwu Guan ${ }^{\mathrm{b}}$, Kexiang Weic, Bin Zhang ${ }^{\mathrm{a}}$
} a. School of Mechanical Engineering, Xiangtan University, Xiangtan, 411105, China

b. Technique Center, Hunan Tyen Machinery Co., Ltd., Hengyang 421000, China

c. Hunan Provincial Key Laboratory of Vehicle Power and Transmission System, Hunan Institute of Engineering, Xiangtan 411104, China

* zuoqingsong100@xtu.edu.cn

Abstract: Improving the NOx conversion efficiency and particulate combustion efficiency under cold start conditions (low temperature conditions) is still the main challenge faced by catalytic gasoline particulate filter system (CGPFs). In this study, the physical and mathematical models of novel CGPFs are proposed based on the computational fluid dynamics software. Then, the models are validated based on experiments, and the performances of conventional and novel CGPFs are analyzed comparatively. The comparison conclusions indicate that the NOx conversion efficiency of the novel CGPFs increases by $3.2 \%$ and the particulate combustion efficiency increases by $2.7 \%$ under the same operating condition. Finally, the effects of exhaust flow $v_{\mathrm{f}}$, exhaust oxygen concentration $C_{\mathrm{o}}$, exhaust NO concentration $C_{\mathrm{NO}}$ and electric heating power $P_{\mathrm{e}}$ on the NOx conversion efficiency and particulate combustion efficiency are investigated. The weights of each influencing parameter on the NOx conversion efficiency and particulate combustion efficiency are explored by orthogonal tests. The conclusions show that the NOx conversion efficiency is increased 

by $3.6 \%$ and the particulate combustion efficiency is increased by $16.7 \%$ compared to the initial

23 condition. This study has an important reference value for improving the purification efficiency of

24 vehicle emission under cold start conditions.

25

26

Keywords: Particulate combustion efficiency; Electric heating power; Catalytic gasoline particulate

27 filter system; Gasoline engine; NOx conversion efficiency; Vehicle emission.
28

29

30

31

32

33

34

35

36

37

38

39

40

41

42 


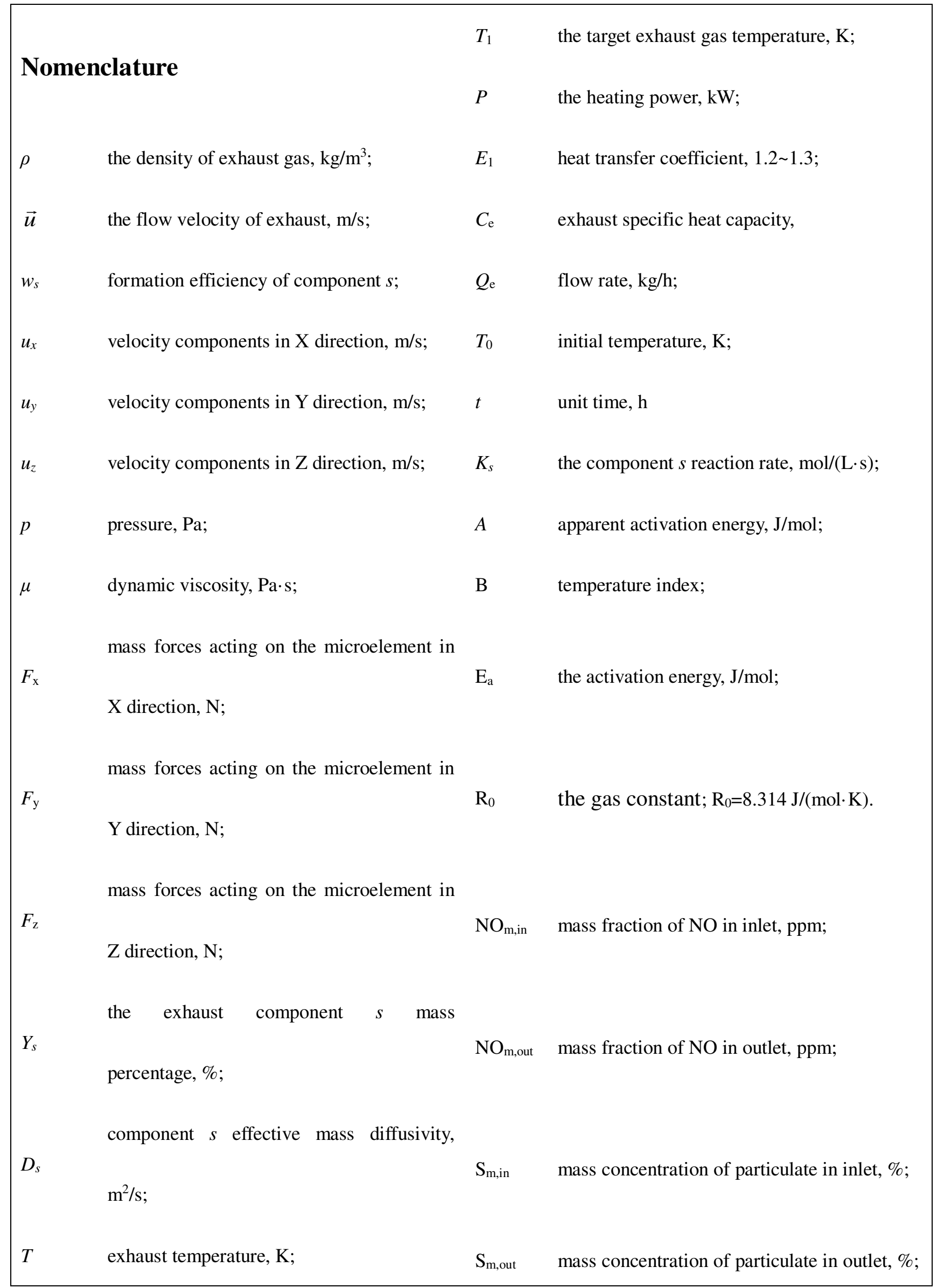




\section{Introduction}

The amount of particulate emissions from gasoline vehicles has already attracted worldwide attention as the number of gasoline vehicles increases rapidly (Wang et al. 2018; Sthel et al. 2019). Increasing the number of particulate emissions will not only seriously endanger human health, but also lead to the formation of disastrous weather (Qian et al. 2019; Dai et al. 2019). Nowadays, although homogeneous mixing technology (Xu et al. 2020) and laminar oxidation technology (Zhong et al. 2016; Distaso et al. 2019) have been successfully applied to gasoline vehicles, the particulate emission of the gasoline vehicles still can not meet the increasingly stringent emission standards (Jain et al. 2017; Chen et al. 2017). Therefore, reducing the particulate emission of gasoline vehicles has become an urgent problem to be solved (Wang et al. 2020). Catalytic gasoline particulate filter system (CGPFs) is currently regarded as one of the most useful automotive exhaust post-treatment technologies (Zuo et al. 2021; Du et al. 2015). As shown in Fig.1, the post-treatment system of the gasoline engine comprises a catalytic converter and a particulate filter (Zhong et al. 2021; Jiang et al. 2017). First, the exhaust gas generated during the vehicle load process enters the catalytic converter (Zhang et al. 2016). When the catalytic converter is working, the HC and CO of the exhaust gas are purified, and $\mathrm{NO}$ is converted into $\mathrm{NO}_{2}$ (Bermudez et al. 2015; E et al. 2020). Then, the exhaust gas with sufficient $\mathrm{NO}_{2}$ concentration flows into the particulate filter (Chen et al. 2014). In the particulate filter, the particles react with $\mathrm{NO}_{2}$ to generate clean exhaust gas (Caliskan of the CGPFs. 


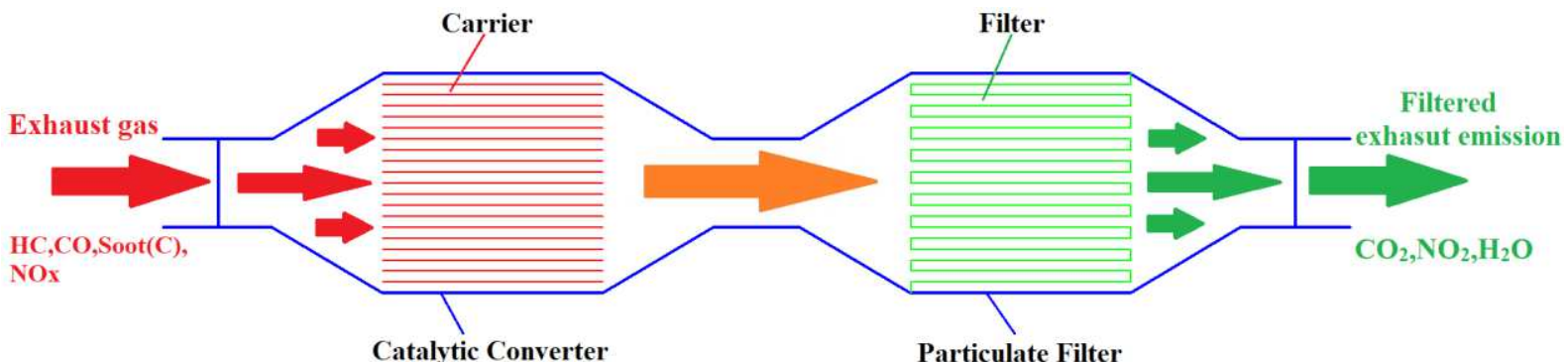

Fig. 1. The conventional model structure of catalytic gasoline particulate filter system. pollutants, the relevant property should be investigated. In the study of particulate filters, many scholars have extensively studied the regeneration characteristics of them. Zhang et al. (2018) developed a one-dimensional full-scale diesel particulate filter (DPF) model to investigate the effect of ash deposition on DPF fuel loss. The results indicated that ash caused $0.02 \%$ to $0.42 \%$ fuel loss; regular ash cleaning saved $0.22 \%$ to $0.69 \%$ of fuel consumption. Jiao et al. (2017) established the reaction mechanism between NOx and PM in DPF, and explored the reaction process of NOx and PM under different inlet conditions. The results showed that when the $\mathrm{NO}_{2}$ in the inlet exhaust accounted for $0.7 \sim 0.8$ of the total NOx content, particulate had a good regeneration effect; when the molar ratio of NOx to PM in the inlet exhaust was greater than 8 , particulate could be completely passively regenerated. Fang et al. (2019) optimized the regeneration property of DPF under $2.5 \mathrm{~g} / \mathrm{L}$ and $5 \mathrm{~g} / \mathrm{L}$ particulate loadings according to an experimental method. It was found that the optimal regeneration temperature was $550{ }^{\circ} \mathrm{C}$ with a flow rate of $16.8 \mathrm{~g} / \mathrm{s}$ for a $2.5 \mathrm{~g} / \mathrm{L}$ particulate load, and the optimal regeneration temperature was $550{ }^{\circ} \mathrm{C}$ with a flow rate of $19.6 \mathrm{~g} / \mathrm{s}$ for a $5 \mathrm{~g} / \mathrm{L}$ particulate load. Choi et al. (2014) compared the pressure drop characteristics of two particulate filters with different porosity based on a visualized experimental method. It was shown that the filter with higher porosity had lower pressure drop and regeneration efficiency for the same particulate load. 
82

83

Ko et al. (2019) analyzed the particle number (PN) emission characteristics of GDI vehicles with and without gasoline particulate filter (GPF) under cold-start conditions. The results showed that the PN emissions of GDI vehicles with GPF were significantly reduced at higher engine speed conditions. Bock et al. (2020) investigated the ability of catalytic GPF to treat dicarboxylic acids in ethanol-blended gasoline emissions according to an experimental method. It was found that the catalytic GPF was able to remove $80 \%$ to $92 \%$ of the dicarboxylic acids from the engine exhaust. E et al. (2020) made a discussion on the effects of various factors on the particulate oxidation property of DPF. They concluded that the particulate oxidation property could be enhanced as the exhaust temperature was $600-750 \mathrm{~K}$, the particulate concentration was $0.06-0.08$, and the microwave heating power was 800-1200 W.

In the study of catalytic converters, Mianzarasvvand et al. (2017) researched the effects of electric heating temperatures and heating times on catalytic converters. They found that the heating temperature was at least $450^{\circ} \mathrm{C}$, and the heater was required to start $35 \mathrm{~s}$ in advance. Broatch et al. (2008) made an in-depth analysis of the intake air heating technology of catalytic converters. They claimed that compared with the electric plug, the intake heating technology can reduce $\mathrm{HC}$ emissions by $13 \%, \mathrm{CO}$ emissions by $5 \%$, and NO emissions by $3 \%$. Horng et al. (2004) investigated the effects of heating energy and $\mathrm{CO}$ content of catalytic converter on $\mathrm{CO}$ conversion rate. The results revealed that the $\mathrm{CO}$ conversion efficiency was improved when the heater was located at the inlet. Vaishnav et al. (2014) explored catalytic converters with diffuser devices at the inlet and demonstrated that the structure optimized the exhaust flow route and improved the purification effect. Day et al. (2020) surveyed various catalysts in catalytic converters, revealed that compared 
with noble metal catalysts, $\mathrm{Cu}$ was the most powerful and active catalyst for $\mathrm{CO}$. Ibrahim et al.

(2018) proposed that insulating material was placed in the carrier channel to investigated the

distribution of the internal flow field and the change of heat diffusion. They found that the gas

uniformity and thermal properties were improved by $5 \%$ and $18 \%$, respectively.

In conclusion, it is found that the current researches on CGPFs focused primarily on various

influence factors such as structural parameters, intake parameters, and different regeneration

technologies on the individual catalytic converter and particulate filter interior flow field, pressure

drop, and regeneration rate. A comprehensive in-depth investigation of the NOx conversion

efficiency and particulate combustion efficiency of CGPFs is relatively lacking. It can be found

through researches ( $\mathrm{Mu}$ et al. 2019) that improving the uniformity of engine exhaust gas flow in

catalytic converters significantly increases the property and lifetime of catalytic converters. In the aspect of active regeneration of particulate filters for low exhaust temperature conditions, there are many researches on the use of microwave heating technology, but there is a lack of research on the use of electric heating technology. Zhong et al (2019) investigated the effect of electrically heated regeneration techniques on the regeneration property of particulate filter at different temperatures but did not study the effect law of electric heating regeneration techniques concerning the CGPFs NOx conversion efficiency and particulate combustion efficiency. Therefore, to enhance the NOx conversion efficiency and particulate combustion efficiency at

121 low exhaust temperature conditions, the physical and mathematical models of a novel CGPFs are 122 proposed based on the computational fluid dynamics software. The properties of conventional and 
experiments. Finally, the influences of flow rate, NO concentration, oxygen concentration, and heating power on the regeneration property of the novel CGPFs are investigated. The weights of each influencing parameter on the NOx conversion efficiency and particulate combustion efficiency are explored by orthogonal tests, and the novel CGPFs is also preferentially selected under simulated working conditions. This work will provide a theoretical basis for further enhancing the purification efficiency of vehicle emission under cold start conditions.

\section{The novel CGPFs model construction}

\subsection{Physical model}

The geometry of the novel CGPFs is shown schematically in Fig 2. It is mainly made up of eight parts, which are inlet tube region, expansion tube region, outer carrier region, inner carrier region, air gap region, filter region, shrink tube region, and outlet tube region. The structural parameters of the novel CGPFs are shown in Table 1.

The process of exhaust gas purification in the novel CGPFs are as follows:

(a) The gasoline engine exhaust gas in low temperature operation flows from the inlet tube into the expansion tube region and is heated by the electric heating equipment in the expansion tube region. (b) The heated exhaust gas undergoes a catalytic reaction in both carrier regions, where the main pollutants of the exhaust gas are purified and $\mathrm{NOx}$ is converted to $\mathrm{NO}_{2}$.

(c) The particulate in the exhaust is trapped by the filter and oxidized by $\mathrm{NO}_{2}$ in the filter region, so as to remove the particulate and achieving the objective of purifying the exhaust gas. tube region. 


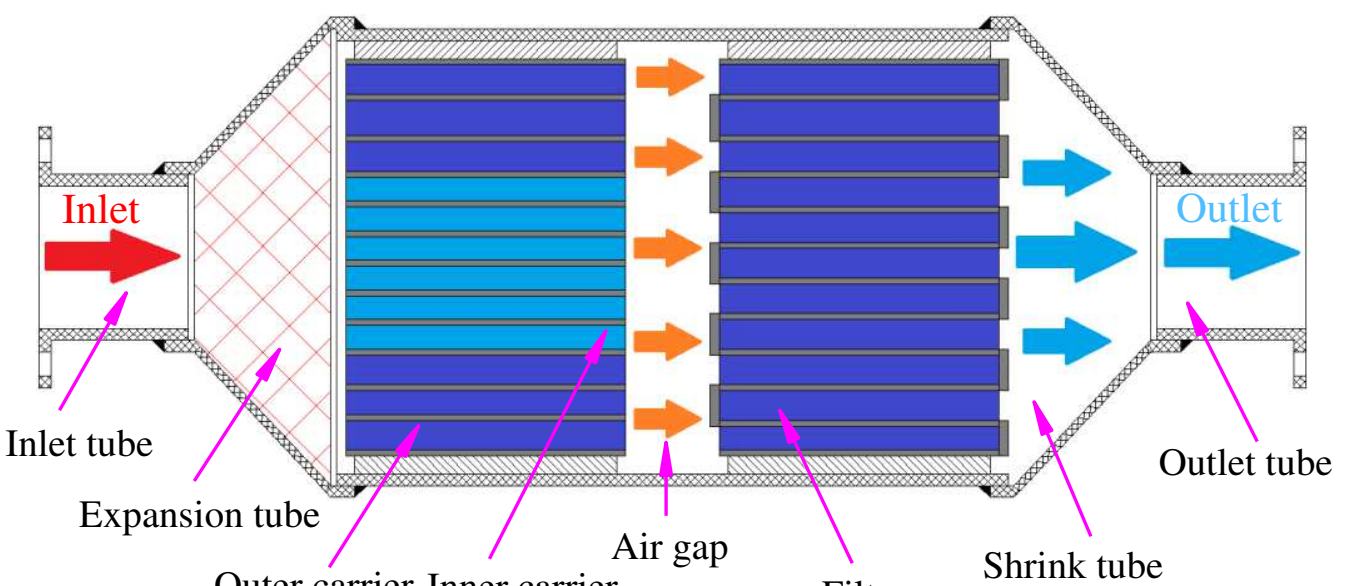

Fig. 2. The geometry of the novel CGPFs.

Table 1 The structural parameters.

\begin{tabular}{ccccccccc}
\hline & Inlet & Expansion & Outer & Inner & Air & & Shrink & Outlet \\
Structures & pipe & pipe & carrier & carrier & gap & & pipe & pipe \\
\hline Length $(\mathrm{mm})$ & 25 & 25 & 100 & 100 & 25 & 100 & 25 & 25 \\
Diameter(mm) & 47 & $/$ & 100 & 50 & 100 & 100 & $/$ & 47 \\
\hline
\end{tabular}

Table 2 shows the carriers and filter related structural parameters.

Table 2 The carrier and filter related structural parameters.

\begin{tabular}{cccccc}
\hline \multirow{2}{*}{ Structures } & Material & Pore density & Wall thickness & Channel diameter & Porosity \\
& & $(\mathrm{cpsi})$ & $(\mathrm{mm})$ & $(\mathrm{mm})$ & 75 \\
\hline \multirow{2}{*}{$\begin{array}{c}\text { Outer carrier } \\
\text { Inner carrier }\end{array}$} & Cordierite & 400 & 1.10 & 0.17 & 72 \\
Filter & Cordierite & 500 & 0.97 & 0.17 & 51 \\
\hline
\end{tabular}

\subsection{Mathematical model of the CGPFs}



et al. 2019): (a) The composition of particulate is pure carbon particles of the same size (b) The void space of the particulate deposition layer on the porous medium wall is randomly distributed, and its size is reasonably uniform; (c) In the same channel, the concentration of each exhaust component is distributed uniformly in the radial direction; (d) It is assumed that the exhaust is an incompressible ideal gas, which satisfies the ideal gas state equation; (e) Only the surface reactions of the components are considered during the regeneration process. equations.

161 (1) The mass conservation equation (E et al. 2020a):

162

$$
\frac{\partial \rho}{\partial \tau}+\nabla \cdot(\rho \cdot \vec{u})=\sum_{s} w_{s}
$$

(2) The momentum conservation equation (Zuo et al. 2021):

$$
\left\{\begin{array}{l}
\frac{\partial\left(\rho u_{x}\right)}{\partial t}+\nabla \cdot\left(\rho \vec{u} u_{x}\right)=-\frac{\partial p}{\partial x} \nabla\left(\mu \cdot \operatorname{gradu}_{x}\right)+F_{x} \\
\frac{\partial\left(\rho u_{y}\right)}{\partial t}+\nabla \cdot\left(\rho \vec{u} u_{y}\right)=-\frac{\partial p}{\partial y} \nabla\left(\mu \cdot \operatorname{grad} u_{y}\right)+F_{y} \\
\frac{\partial\left(\rho u_{z}\right)}{\partial t}+\nabla \cdot\left(\rho \vec{u} u_{z}\right)=-\frac{\partial p}{\partial z} \nabla\left(\mu \cdot \operatorname{grad} u_{z}\right)+F_{z}
\end{array}\right.
$$

165 (3) The component conservation equation ( $\mathrm{E}$ et al. 2020b):

$$
\nabla \cdot\left(\rho \vec{u} Y_{s}\right)=-\left[\frac{\partial}{\partial x}\left(\rho D_{s} \frac{\partial Y_{s}}{\partial x}\right)+\frac{\partial}{\partial y}\left(\rho D_{s} \frac{\partial Y_{s}}{\partial y}\right)+\frac{\partial}{\partial z}\left(\rho D_{s} \frac{\partial Y_{s}}{\partial z}\right)\right]+W_{s}
$$

167 (4) The electric heating catalytic reaction rate equation (Jiao et al. 2017):

$$
T_{1}=\frac{P \cdot 3600}{E_{1} \cdot C_{e} \cdot Q_{e} \cdot t}+T_{0}
$$


The software Fluent is used to solve the above models. The component transport model and standard $k-\varepsilon$ model are applied to dispose of the chemical reaction model and flow model (White et et al. 2020; Deng et al. 2017). The residual error of energy equation is $1 \times 10^{-6}$, while the residual error of continuity, momentum, and component equations is $1 \times 10^{-3}$. Table $\mathbf{3}$ shows the initial boundary conditions.

\begin{tabular}{cc}
\hline Parameters & Values \\
Flow rate & $20 \mathrm{~g} / \mathrm{s}$ \\
Heating power & $0.5 \mathrm{~kW}$ \\
Exhaust oxygen concentration & $1.6 \%$ \\
Exhaust NO concentration & $800 \mathrm{ppm}$ \\
Particulate mass concentration & $1 \mathrm{~g} \cdot \mathrm{L}^{-1}$ \\
Inlet boundary & Mass flow inlet \\
Outlet boundary & Pressure outlet \\
\hline
\end{tabular}
performed. 


\begin{tabular}{cccc}
\hline No. & Elementary reactions & Frequency factor $\left(\mathrm{s}^{-1}\right)$ & Activation energy $(\mathrm{kJ} / \mathrm{mol})$ \\
\hline $\mathrm{R}_{1}$ & $\mathrm{NO}+1 / 2 \mathrm{O}_{2} \rightarrow \mathrm{NO}_{2}$ & $1.0 \mathrm{E}+13$ & 600 \\
$\mathrm{R}_{2}$ & $\mathrm{NO}_{2} \rightarrow \mathrm{NO}+1 / 2 \mathrm{O}_{2}$ & $2.0 \mathrm{E}+12$ & 26825 \\
$\mathrm{R}_{3}$ & $\mathrm{C}(\mathrm{s})+\mathrm{NO}_{2} \rightarrow \mathrm{CO}+\mathrm{NO}$ & $3.9 \mathrm{E}+13$ & 177 \\
$\mathrm{R}_{4}$ & $\mathrm{C}(\mathrm{s})+1 / 2 \mathrm{O}_{2} \rightarrow \mathrm{CO}$ & $2.0 \mathrm{E}+13$ & 576 \\
$\mathrm{R}_{5}$ & $\mathrm{CO}+1 / 2 \mathrm{O}_{2} \rightarrow \mathrm{CO}_{2}$ & $2.5 \mathrm{E}+12$ & 47800 \\
\hline
\end{tabular}

\subsection{Grid independence research} regular hexahedron are generated.

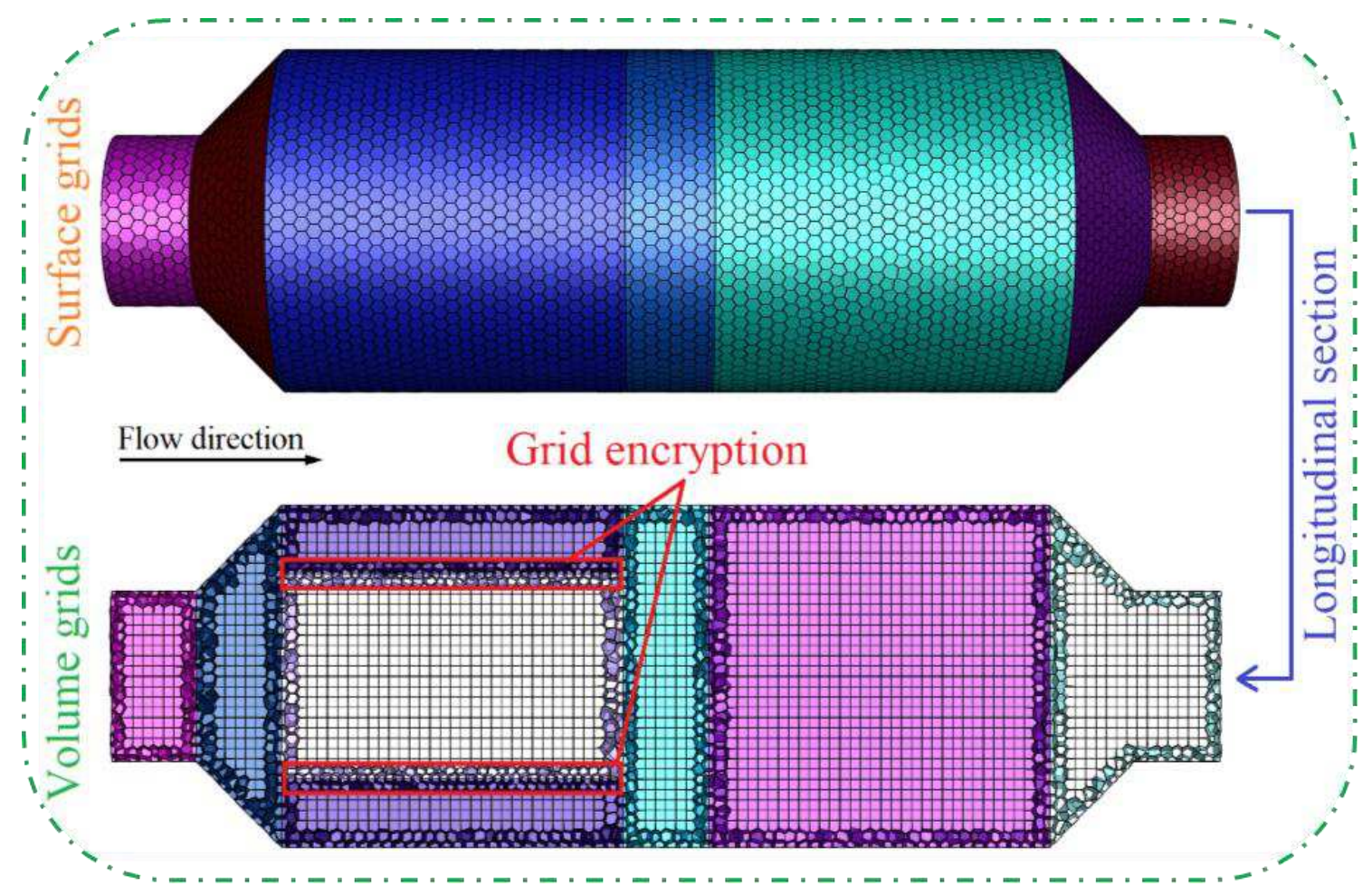

Fig. 3. The medium mesh model. 
mesh model), and 104,309 (coarse mesh model), respectively. In order to obtain the grid model in numerical simulation accuracy and shorten the calculation time.

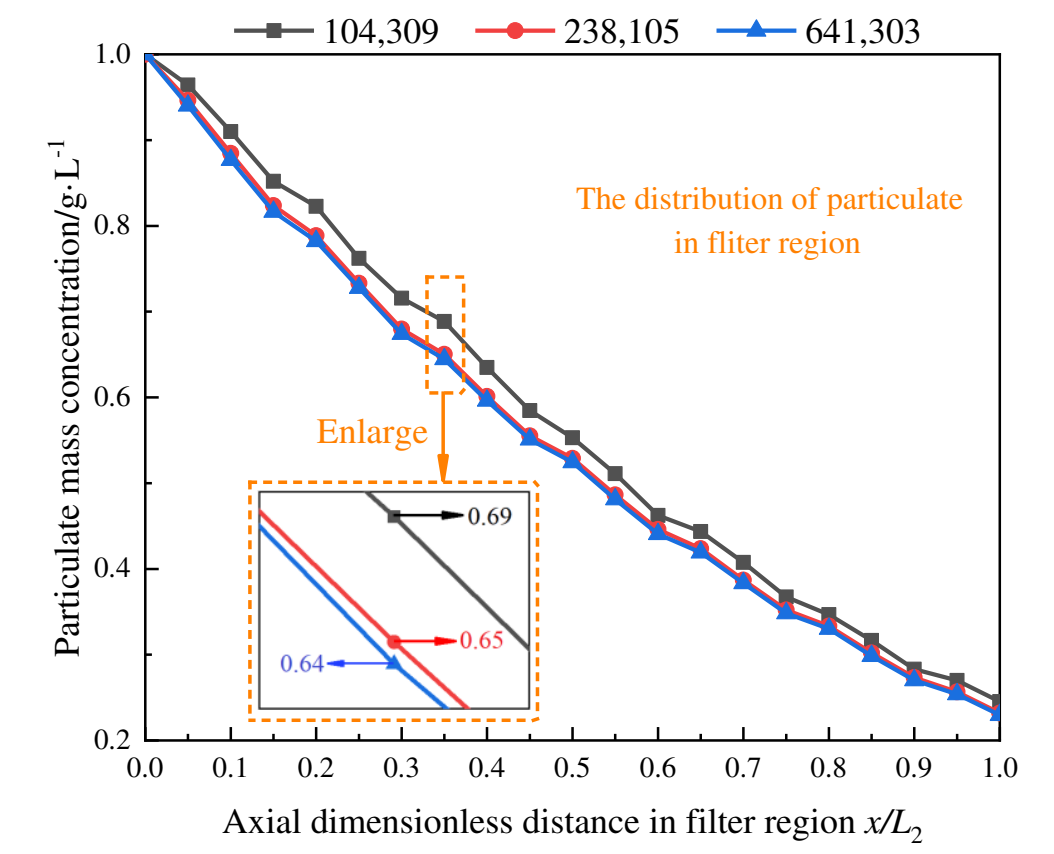

Fig. 4. Effects of the grid numbers on particulate mass concentration models. As we can see from the figure, when the dimensionless distances are identical, the model is basically the same. Therefore, considering the impact of the number of grids on the computational resources, the grid model with 238,105 grids can meet the requirements of the detail, Fig 3 shows the medium grid mesh model of the novel CGPFs.

Fig. 4 shows the distribution pattern of the mass concentration of particulate in different grid difference of particulate mass concentration between the medium mesh model and the fine mesh

In order to determine the accuracy of the simulation calculation results, the novel CGPFs models are validated according to experiment tests. Fig. 5 shows the experimental equipment. engine, flowmeter, differential pressure sensor, GPF, gas analyzer, computer, valve, power supply, 

information about the GDI engine is listed in Table 5.

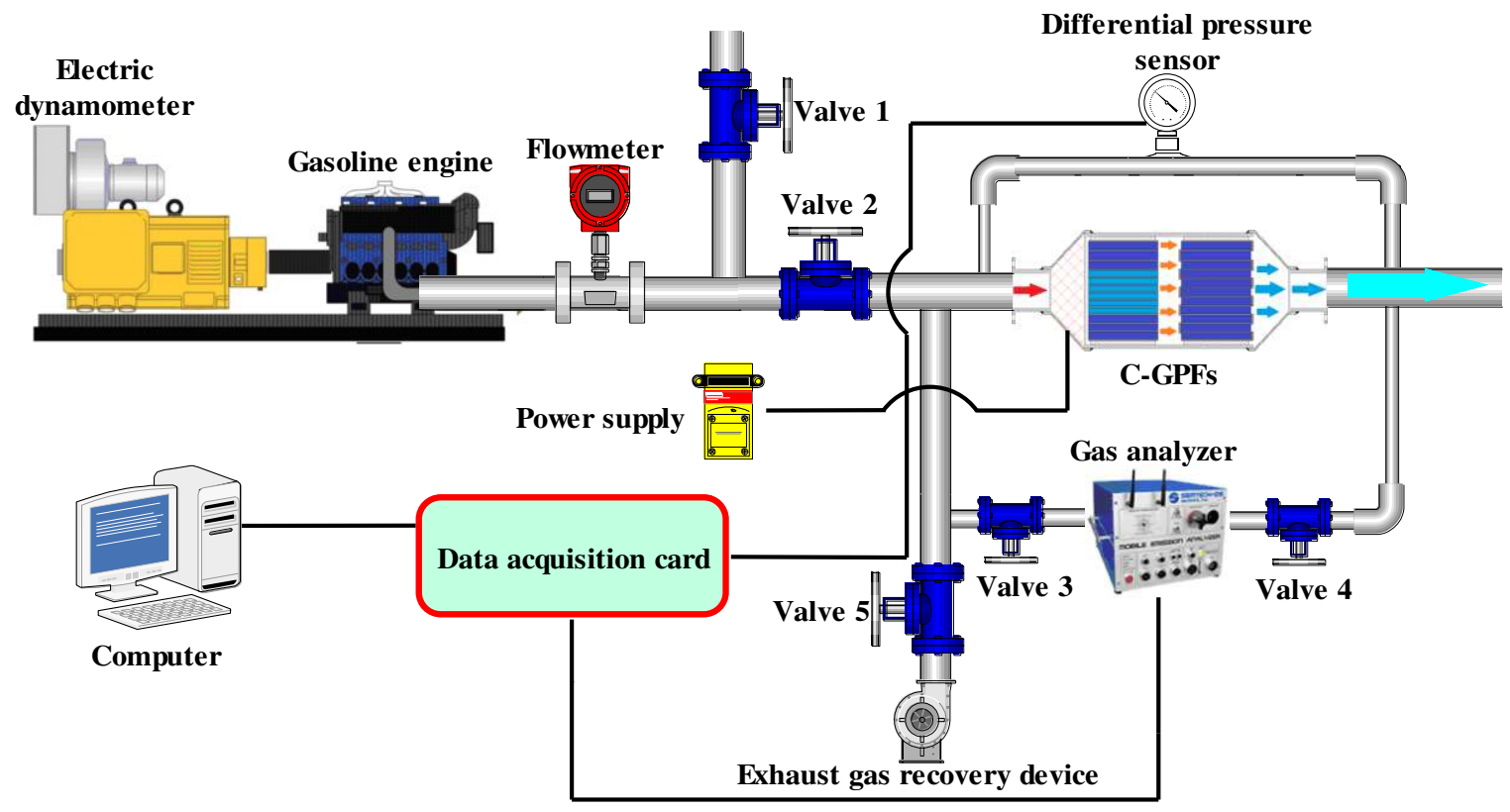

Fig. 5. Various experimental equipment used in the experiment test

Table 5 Technical parameters of the GDI engine

\begin{tabular}{ccc}
\hline SN & Parameter & value \\
\hline 1 & Engine displacement (L) & 1.3 \\
2 & Cylinder number & 4 \\
3 & Arrangement form & Transverse position \\
4 & Bore diameter (mm) & 71 \\
5 & stroke (mm) & 82 \\
6 & Rated speed (rpm) & 5400 \\
\hline
\end{tabular}


213 DiCom-4000 gas analyzer produced by AVL is used to detect pollutants such as $\mathrm{HC}, \mathrm{CO}, \mathrm{CO}_{2}, \mathrm{NOx}$

214 and $\mathrm{O}_{2}$ in the exhaust gas of gasoline engines. The basic technical parameters are shown in Table 6.

Table 6 The DiCom-4000 gas analyzer related parameters

\begin{tabular}{ccc}
\hline Pollutant compositions & Measuring ranges & errors \\
\hline $\mathrm{HC}$ & $0-2 \%$ & $\pm 0.0001 \%$ \\
$\mathrm{CO}$ & $0-10 \%$ & $\pm 0.01 \%$ \\
$\mathrm{CO}_{2}$ & $0-20 \%$ & $\pm 0.1 \%$ \\
$\mathrm{NOx}$ & $0-5000 \mathrm{ppm}$ & $\pm 1 \mathrm{ppm}$ \\
$\mathrm{O}_{2}$ & $0-23 \%$ & $\pm 0.01 \%$ \\
\hline
\end{tabular}

Fig.6(b), it is clear that the relative error of the pressure drop ranges from $2.6 \%$ to $3.7 \%$, with a and simulation results. However, due to model simplification, experimental measurement error, and experimental instrument accuracy, there is still some discrepancy between the two results, but the difference is small (less than $5 \%$ ).

224 Arunachalam et al. 2020): (1) In the simulation process, the flow of the exhaust gas in each channel 225 is uniform in the radial direction, but in fact, the flow in each channel is not completely uniform. (2)

226 There are unavoidable errors in the test process. (3) In the simulation process, the boundary 227 conditions of the intake pipe and outlet pipe are adiabatic walls, but in fact, there is a heat transfer 

phenomenon. Therefore, the mathematical models of the novel CGPFs meet the requirements of numerical simulation calculations and can be used to predict flow and reaction characteristics.

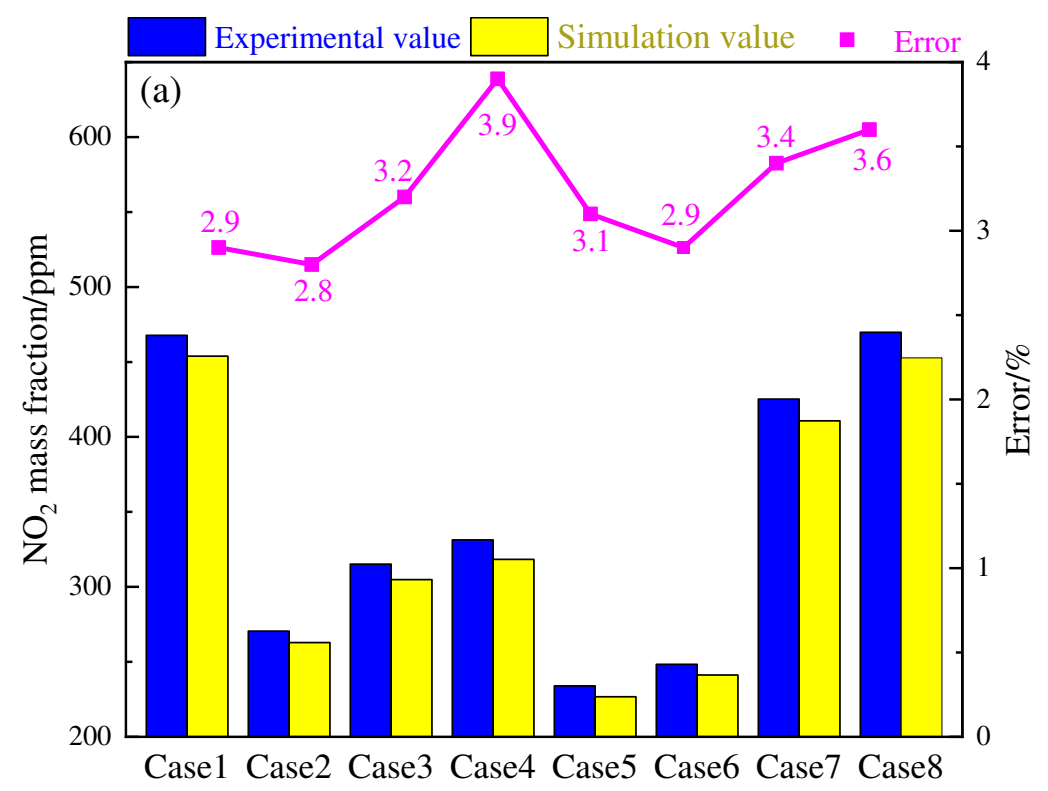

(a) $\mathrm{NO}_{2}$ mass fraction

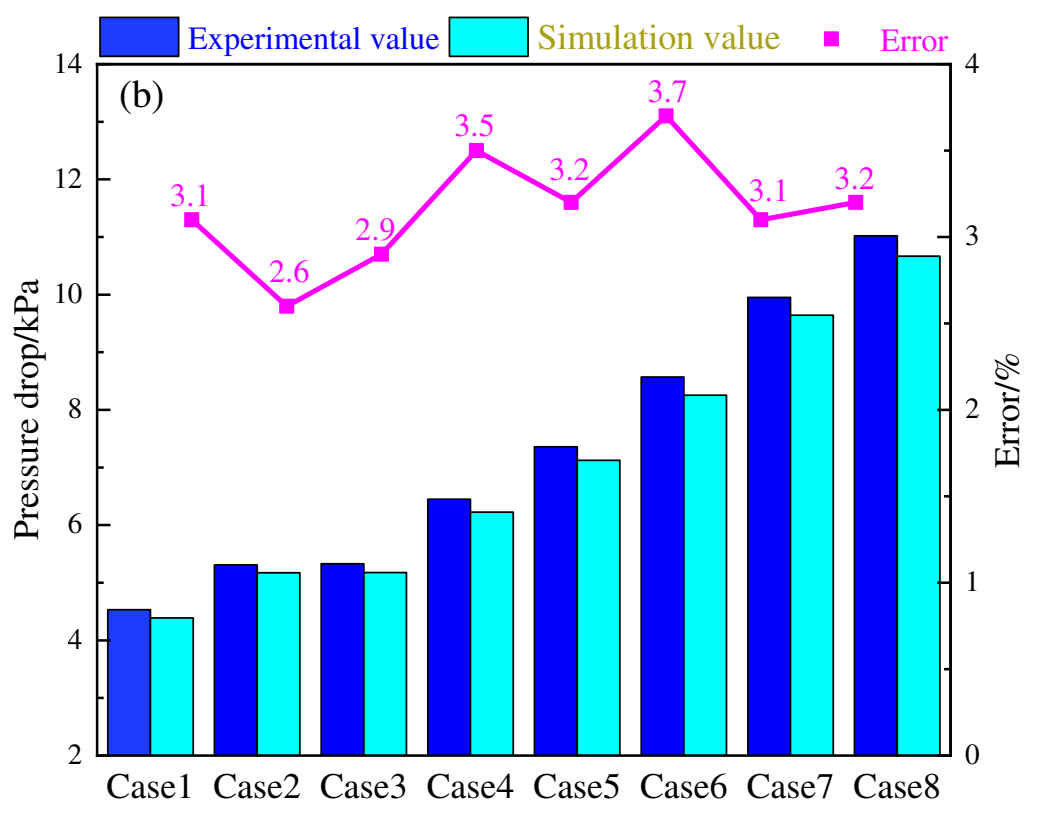

(b) Pressure drop

Fig. 6. Comparison of the experimental values and simulation values

In this work, the NOx conversion efficiency $\beta$ can be defined as: 


$$
\beta=\frac{\mathrm{NO}_{\mathrm{min}}-\mathrm{NO}_{\mathrm{m} \text { out }}}{\mathrm{NO}_{\mathrm{m} \text { in }}} \times 100 \%
$$

The particulate combustion efficiency $\varepsilon$ can be defined as:

$$
\varepsilon=\frac{\mathrm{S}_{\mathrm{m} \text { in }}-\mathrm{S}_{\mathrm{m} \text { out }}}{\mathrm{S}_{\mathrm{m} \text { in }}} \times 100 \%
$$

The regeneration property of conventional and novel CGPFs at different exhaust temperatures

241 is compared and analyzed by changing only the exhaust temperature while the electric heating 242 power is constant at $0.5 \mathrm{~kW}$ and other operating conditions are the same. Fig. 7(a) and Fig. 7(b) 243 show the variation patterns of catalytic efficiency of NO and combustion efficiency of particulate of 244 the two CGPFs at various temperatures, respectively.

From Fig. 7(a), we can see that the catalytic efficiency of NO of both CGPFs shows a tendency to increase and then decrease as the exhaust temperature increase. The novel CGPFs have 247 a higher catalytic efficiency of $\mathrm{NO}$ at identical temperatures. The maximum values of NOx 248 conversion efficiency for both conventional and novel CGPFs are obtained at $590 \mathrm{~K}$, with values of $24958.6 \%$ and $61.8 \%$, respectively. Thus, the maximum NOx conversion efficiency of the novel CGPFs 250 increases by $3.2 \%$.

As we can see from Fig. 7(b), the combustion efficiency of particulate in both CGPFs shows a tendency to increase rapidly and then stabilize with the increase of exhaust temperature. At identical 253 exhaust temperatures, the novel CGPFs have higher particulate combustion efficiency. At an 254 exhaust temperature of $590 \mathrm{~K}$, the combustion efficiency of particulate is $74.1 \%$ and $76.8 \%$ for the conventional and novel CGPFs, respectively, and the novel CGPFs increase the particulate combustion efficiency by $2.7 \%$. In summary, the novel CGPFs can improve the catalytic efficiency 
of NO and combustion efficiency of particulate at identical working states.

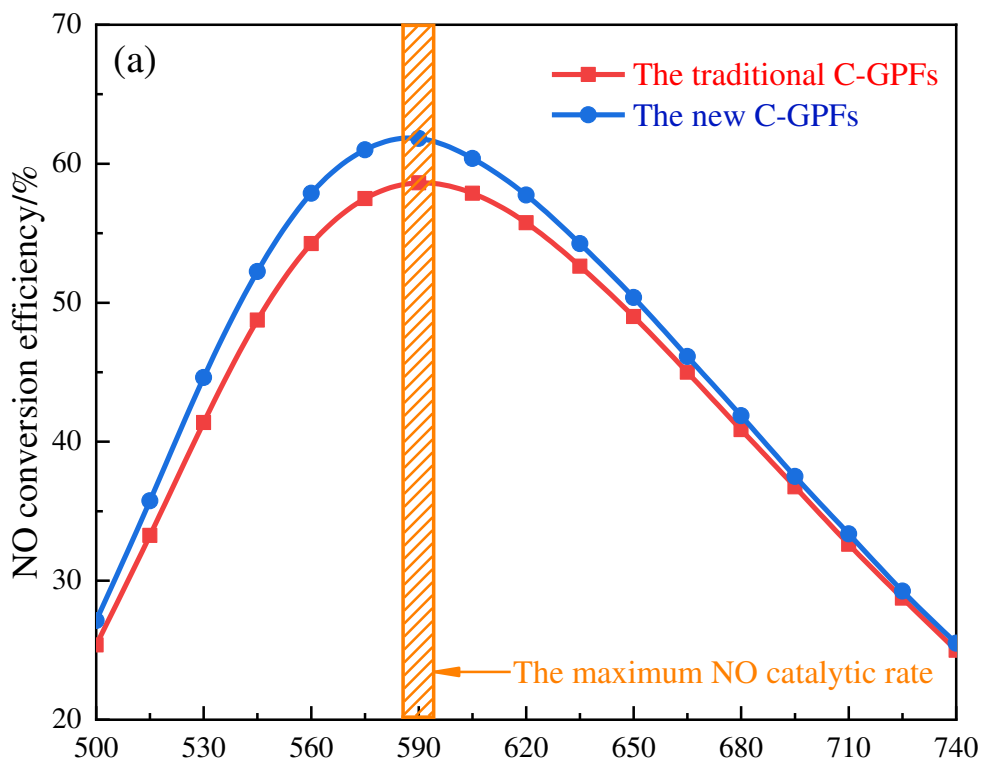

Temperature/K

(a) NOx conversion efficiency

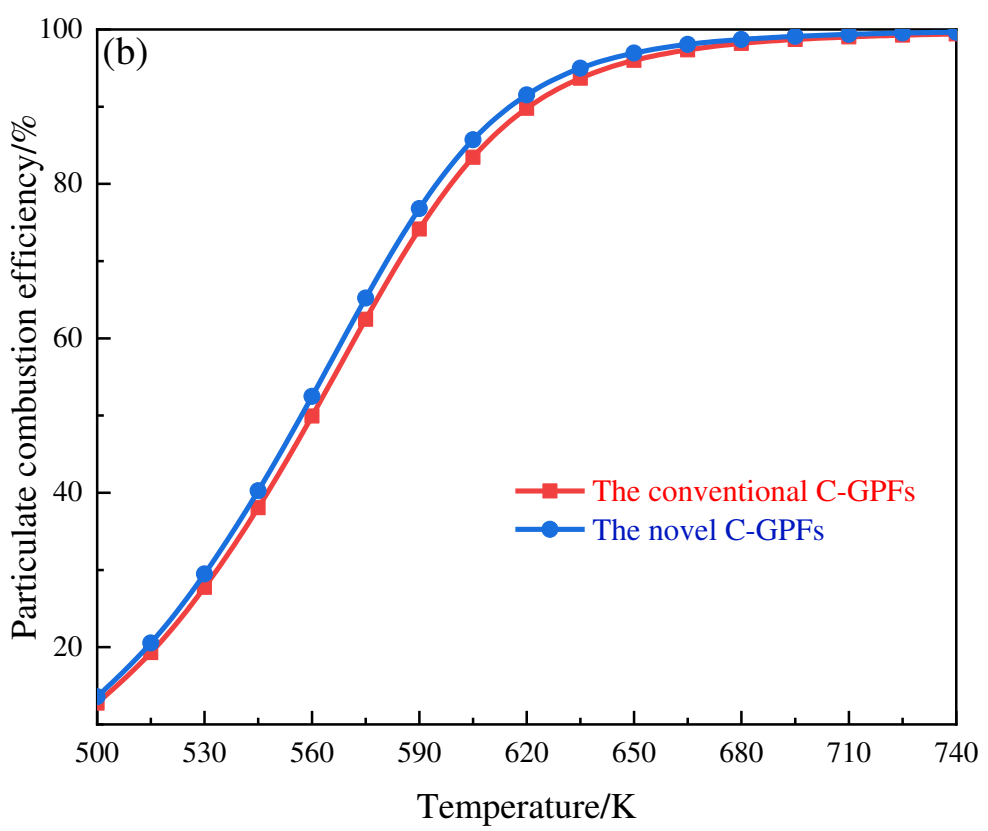

(b) Particulate combustion efficiency

Fig. 7. Comparison results of the two CGPFs at various temperatures.

\section{Results and discussions}

In order to analyze the effect of different influencing parameters on the emission control of 
gasoline vehicle exhaust pollutants, the effects of exhaust flow $v_{\mathrm{f}}$, exhaust oxygen concentration $C_{\mathrm{o}}$,

exhaust NO concentration $C_{\mathrm{NO}}$ and electric heating power $P_{\mathrm{e}}$ on NOx conversion efficiency and particulate combustion efficiency are investigated in detail.

\subsection{Influence analysis of NOx conversion efficiency}

Fig. 8(a) shows the effect of $v_{\mathrm{f}}$ on the NOx conversion efficiency at various exhaust

temperatures. From the figure, the NOx conversion efficiency at different $v_{\mathrm{f}}$ tends to increase and

then decrease. At exhaust temperatures equal to $500 \mathrm{~K}$, the NOx conversion efficiency at the $v_{\mathrm{f}}$ of

$24 \mathrm{~g} / \mathrm{s}, 20 \mathrm{~g} / \mathrm{s}$, and $16 \mathrm{~g} / \mathrm{s}$ are $20 \%, 27 \%$, and $38 \%$, respectively. This is due to the low catalyst activity at low exhaust temperatures. With increasing exhaust temperature, CGPFs with low $v_{\mathrm{f}}$ reach their maximum NOx conversion efficiency at a lower temperature, and the maximum NOx conversion efficiency is higher. The maximum conversion efficiency of NOx is enhanced from 57\% to $66 \%$ as the $v_{\mathrm{f}}$ decreases from $24 \mathrm{~g} / \mathrm{s}$ to $16 \mathrm{~g} / \mathrm{s}$. This is because as the exhaust gas composition

277 remains unchanged, the lower $v_{\mathrm{f}}$ results in slower exhaust flow velocity in the CGPFs, which 278 increases the time for the catalyst coating in the carrier areas to come into contact with the exhaust gas. At the identical time, the exhaust gas heats up for a longer time in the heating area and the temperature of the exhaust gas rises higher, leading to a more complete reaction of NO with the 281 oxidizer in the presence of the catalyst. At higher exhaust temperatures, the rate of $\mathrm{NO}_{2}$ 282 decomposition gradually exceeds the rate of NO catalytic reaction. Thus, the conversion efficiency 283 of NOx starts to decrease with increasing temperature. Define the catalytic efficiency of NO above $28450 \%$ as the reliable working temperature interval. Therefore, a proper reduction of the $v_{\mathrm{f}}$ is 

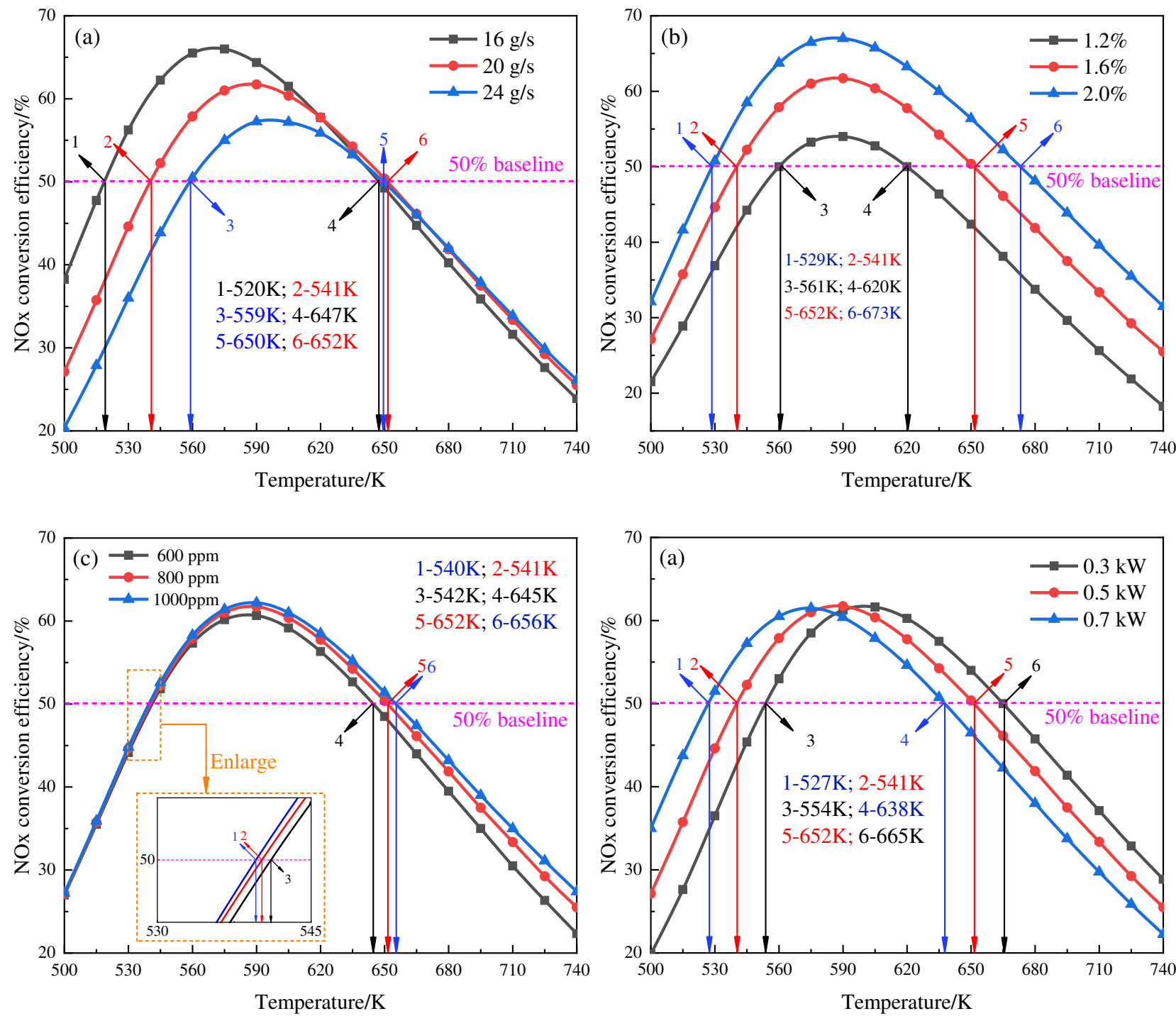

Fig.8. NOx conversion efficiency

Fig. 8(b) shows the effect of the $C_{\mathrm{o}}$ on the NOx conversion efficiency at various exhaust

temperatures. From the figure, the conversion efficiency of NOx under various $C_{\mathrm{o}}$ conditions tends to increase and then decrease. At identical temperatures, the conversion efficiency of NOx is higher at higher $C_{\mathrm{o}}$ conditions. At the exhaust temperature of $500 \mathrm{~K}$, the conversion efficiency of NOx is $18.3 \%, 25.5 \%$, and $31.5 \%$ at an $C_{0}$ of $1.2 \%, 1.6 \%$, and $2.0 \%$, respectively. The maximum conversion efficiency of NOx under different $C_{\mathrm{o}}$ conditions is reached at an exhaust temperature of 
590K. The maximum conversion efficiency of NOx is enhanced from $54 \%$ to $67 \%$ with the $C_{\mathrm{o}}$ increases from $1.2 \%$ to $2.0 \%$. This is because that oxygen is the reactant in the catalytic reaction of

NOx, accelerates the rate of reaction in the presence of a catalyst when the $C_{\mathrm{o}}$ is increased. As a result, the NOx conversion efficiency is higher at higher $C_{\mathrm{o}}$ at identical exhaust temperatures. At higher exhaust temperatures, the rate of $\mathrm{NO}_{2}$ decomposition gradually exceeds the rate of $\mathrm{NO}$ catalytic reaction. Thus, the NOx conversion efficiency gradually decreases with increasing temperature. Based on the determination of the reliable working temperature range, an appropriate increase in $C_{\mathrm{o}}$ is beneficial for increasing the NOx conversion efficiency and increasing the reliable working temperature range.

Fig. 8(c) shows the influence of the $C_{\mathrm{NO}}$ on the NOx conversion efficiency at various exhaust temperatures. From the figure, the NOx conversion efficiency at different NO concentrations tends to increase and then decrease. The conversion efficiency of NOx is higher at higher $C_{\mathrm{NO}}$ conditions at identical temperatures. The efficiency of NOx is around $27 \%$ at $600 \mathrm{ppm}, 800 \mathrm{ppm}$, and 1000 ppm of different $C_{\mathrm{NO}}$ conditions at $500 \mathrm{~K}$. As the $C_{\mathrm{NO}}$ increases from $600 \mathrm{ppm}$ to $1000 \mathrm{ppm}$, the maximum NOx conversion efficiency is increased from $60.7 \%$ to $62.2 \%$. This is because although

311 NO is used as a reactant in the catalytic reaction, in exhaust gas, the oxygen concentration is much higher than the $C_{\mathrm{NO}}$, and increasing the NO concentration has less effect on the catalytic reaction.

313 As the NO concentration in the exhaust gas increases, the catalytic reaction under different $C_{\mathrm{NO}}$ conditions can reach a complete reaction state. Therefore, at identical exhaust temperatures, the $C_{\mathrm{NO}}$ has less influence on the NOx conversion efficiency. At higher exhaust temperatures, the rate of 
efficiency gradually decreases with increasing temperature. Based on the determination of the

318 reliable working temperature range, an appropriate increase in $C_{\mathrm{NO}}$ is beneficial for increasing the

319 NOx conversion efficiency and increasing the reliable working temperature range.

Fig. 8(d) shows the influence of $P_{\mathrm{e}}$ on the NOx conversion efficiency at various exhaust

temperatures. From the figure, the conversion efficiency of $\mathrm{NOx}$ at different $P_{\mathrm{e}}$ conditions tends to increase and then decrease with the increases of exhaust temperature. The conversion efficiency of NOx is $20 \%, 27 \%$, and $35 \%$ at $0.3 \mathrm{~kW}, 0.5 \mathrm{~kW}$, and $0.7 \mathrm{~kW}$ of $P_{\mathrm{e}}$ conditions at an exhaust temperature of $500 \mathrm{~K}$. This is due to the low catalyst activity at low exhaust temperatures. The CGPFs with higher $P_{\mathrm{e}}$ condition reaches the maximum NOx conversion efficiency at lower exhaust temperature with increasing exhaust temperature, and the maximum conversion efficiencies of NOx at various $P_{\mathrm{e}}$ conditions are the same. The maximum conversion efficiency of NOx is maintained at $62 \%$ when the $P_{\mathrm{e}}$ enhances from $0.3 \mathrm{~kW}$ to $0.7 \mathrm{~kW}$. This is mainly because the composition and

329 flow characteristics of the exhaust gas remain unchanged, and the exhaust gas under different $P_{\mathrm{e}}$ conditions can reach the same degree of reaction state. In the case of high $P_{\mathrm{e}}$, the exhaust gas raises

331 the temperature in the heated area faster. Therefore, when the $P_{\mathrm{e}}$ is high, the NO catalytic reaction 332 and the $\mathrm{NO}_{2}$ decomposition reaction reach equilibrium more quickly. At higher exhaust 333 temperatures, the rate of $\mathrm{NO}_{2}$ decomposition gradually exceeds the rate of $\mathrm{NO}$ catalytic reaction. 334 Thus, the NOx conversion efficiency gradually decreases with increasing temperature. Thus, an 335 appropriate increase in $P_{\mathrm{e}}$ is beneficial for increasing the NOx conversion efficiency and increasing 336 the reliable working temperature range. 
Fig. 9(a) shows the pattern of the effect of $v_{\mathrm{f}}$ on the combustion efficiency of particulate at

339 various exhaust temperatures. From the figure, the particulate combustion efficiency at different $v_{\mathrm{f}}$ 340 conditions shows a tendency to increase rapidly and then stabilize with increasing temperature.

341 When the $v_{\mathrm{f}}$ is lower, the combustion efficiency of particulate is greater at identical exhaust 342 temperatures. The combustion efficiency of particulate is less than $25 \%$ at exhaust temperatures 343 equal to $500 \mathrm{~K}$, and the combustion efficiency of particulate is greater than $90 \%$ at exhaust 344 temperatures greater than $650 \mathrm{~K}$. This is because that the catalyst activity gradually increases and 345 the rate of particulate oxidation accelerates, which causes the particulate combustion efficiency to 346 increase rapidly while the exhaust temperature enhances. When the $v_{\mathrm{f}}$ is low, the convective heat 347 exchange of the exhaust gas in the heated area is enhanced and the exhaust gas temperature rises 348 higher. As a result, at identical exhaust temperatures, the combustion efficiency of particulate is 349 higher at lower $v_{\mathrm{f}}$.

Fig. 9(b) shows the pattern of the effect of $C_{\mathrm{o}}$ on the particulate combustion efficiency at 351 various exhaust temperatures. From the figure, the particulate combustion efficiency at different $C_{\mathrm{o}}$ 352 conditions shows a tendency to increase rapidly and then stabilize with increasing temperature. At 353 identical exhaust temperatures, the combustion efficiency of particulate is higher while the $C_{\mathrm{o}}$ 354 condition is greater. At exhaust temperatures equal to $500 \mathrm{~K}$, the oxidation efficiencies of particulate 355 are less than $20 \%$ at different $C_{\mathrm{o}}$ conditions, and the oxidation efficiencies of particulate are greater 356 than $90 \%$ at exhaust temperatures greater than $635 \mathrm{~K}$. This is because that the catalyst activity 357 gradually increases and the rate of particulate oxidation accelerates with the exhaust temperature 358 increases, resulting in a rapid increase in the rate of particulate oxidation. As the $C_{\mathrm{o}}$ increases, the 
rate and amount of $\mathrm{NO}_{2}$ generation in the carrier areas increases, resulting in a larger $\mathrm{NO}_{2}$ effective particulate cleaning effect.
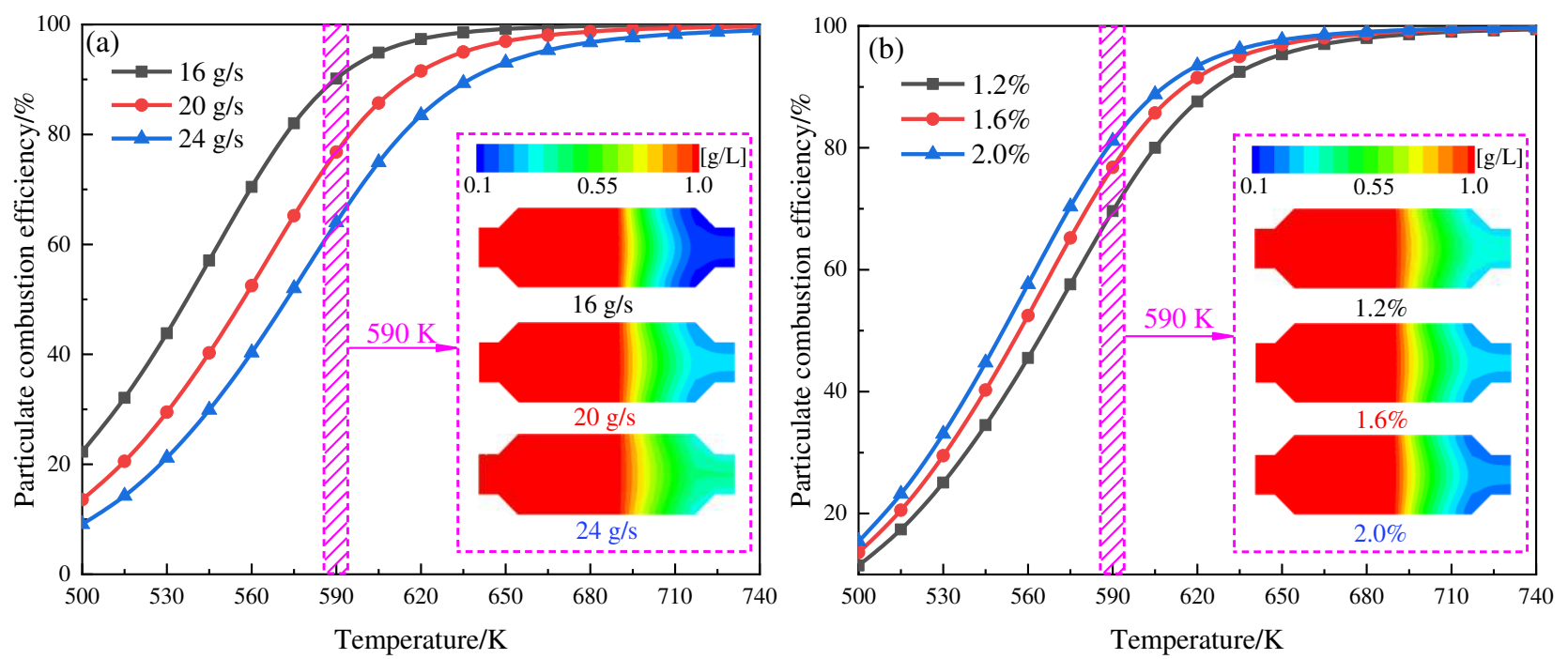

364
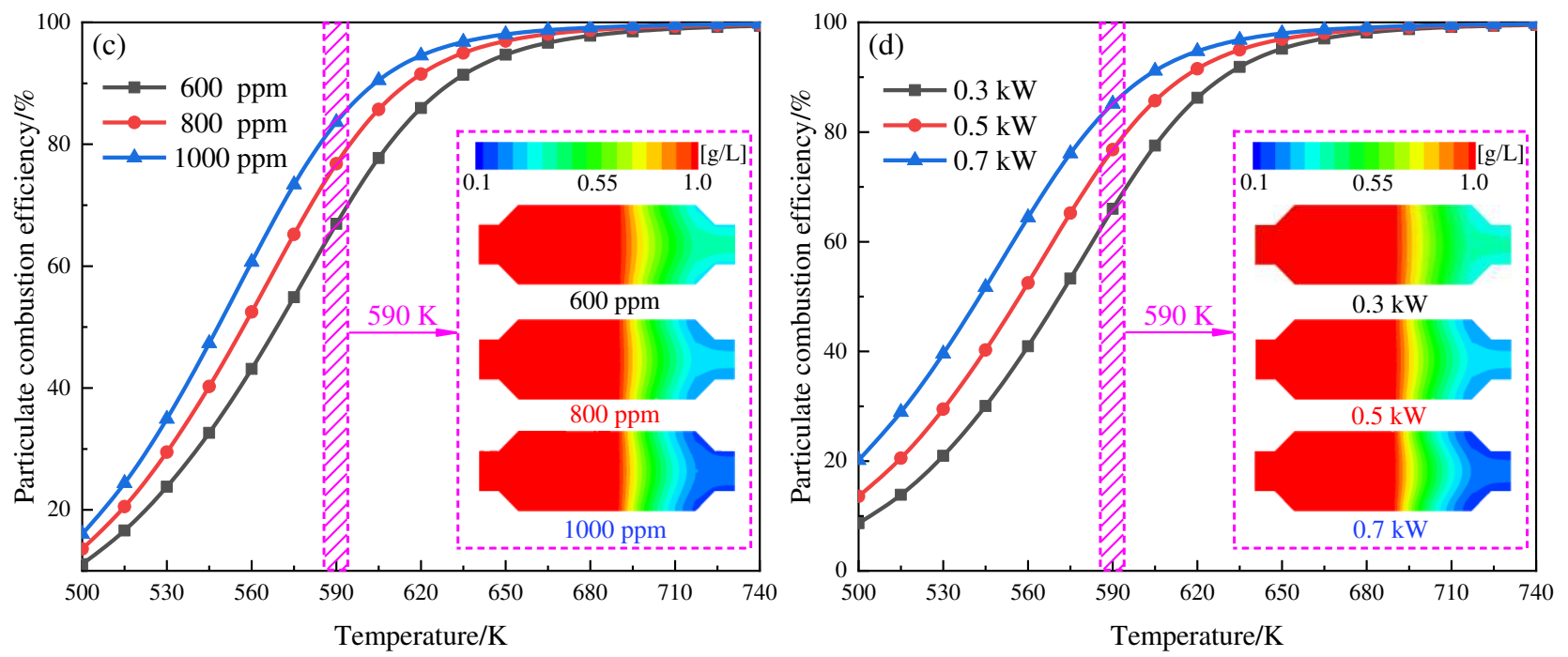

Fig. 9. Particulate combustion efficiency.

Fig. 9(c) shows the pattern of the influence of $C_{\mathrm{NO}}$ on the particulate combustion efficiency at 
$C_{\mathrm{NO}}$ conditions shows a tendency to increase rapidly and then stabilize with increasing temperature.

370 The combustion efficiency of particulate is higher when the $C_{\mathrm{NO}}$ condition is greater at identical

371 exhaust temperatures. The oxidation efficiencies of particulate are less than $20 \%$ at different $C_{\mathrm{NO}}$

372 conditions at $500 \mathrm{~K}$, and the oxidation efficiencies of particulate are greater than $90 \%$ at exhaust

373 temperatures greater than $635 \mathrm{~K}$. This is because that the temperature is low, resulting in a lower

374 rate of oxidation. The catalyst activity gradually increases and the rate of particulate oxidation

375 accelerates as the exhaust temperature increases, resulting in a rapid increase in the rate of

376 particulate oxidation. As the $C_{\mathrm{NO}}$ increases, the $\mathrm{NO}_{2}$ concentration at the carrier outlet also increases,

377 resulting in a faster combustion efficiency of particulate in the filter area. As a result, at identical

378 exhaust temperatures, the combustion efficiency of particulate is higher at greater $C_{\mathrm{NO}}$. Thus, an 379 appropriate increase in $C_{\mathrm{NO}}$ will help to reach a more effective particulate cleaning effect.

Fig. 9(d) shows the pattern of the influence of $P_{\mathrm{e}}$ on the particulate combustion efficiency at

381 various exhaust temperatures. From the figure, the particulate combustion efficiency at different $P_{\mathrm{e}}$

382 conditions shows a tendency to increase rapidly and then stabilize with increasing temperature. At

383 identical exhaust temperatures, the combustion efficiency of particulate is higher while the $P_{\mathrm{e}}$ is

384 larger. At exhaust temperatures equal to $500 \mathrm{~K}$, the oxidation efficiencies of particulate are less than

$38525 \%$ at various $P_{\mathrm{e}}$ conditions. This is because that the temperature is low, resulting in a lower rate of

386 oxidation. The catalyst activity gradually increases and the rate of particulate oxidation accelerates

387 as the exhaust temperature increases, resulting in a rapid increase in the rate of particulate oxidation.

388 When the $P_{\mathrm{e}}$ is higher, the exhaust gas temperature increases even more. The oxidation efficiencies

389 of particulate are greater than $90 \%$ at exhaust temperatures greater than $635 \mathrm{~K}$. Therefore, at 
identical exhaust temperatures, the combustion efficiency of particulate is higher with larger $P_{\mathrm{e}}$.

391 Thus, an appropriate increase in $P_{\mathrm{e}}$ will help to reach a more effective particulate cleaning effect.

392

\subsection{The distribution pattern of NO mass fraction}

From Fig. 10(a), the mass fraction of NO decreases gradually with increasing dimensionless distance $x / L_{1}$ at different $v_{\mathrm{f}}$. The mass fraction of NO decreases faster at lower $v_{\mathrm{f}}$, and the mass fractions of NO are minimized at the carrier outlet at different $v_{\mathrm{f}}$. As the $v_{\mathrm{f}}$ reduces from $24 \mathrm{~g} / \mathrm{s}$ to 16 $\mathrm{g} / \mathrm{s}$, the minimum NO mass fraction value is reduced from $342 \mathrm{ppm}$ to $285 \mathrm{ppm}$. The result is mainly due to the longer contact time between the exhaust gas and the catalyst coating in the carrier areas as the $v_{\mathrm{f}}$ decreases, while convective heat transfer is enhanced and the exhaust gas temperature increases, which results in a faster decrease in NO mass fraction. Thus, a proper reduction of the $v_{\mathrm{f}}$ is beneficial to the NOx conversion efficiency.

As we can see from Fig. 10(b), the mass fraction of NO decreases gradually with increasing dimensionless distance $x / L_{1}$ at different $C_{0}$ conditions. The mass fraction of NO decreases faster at greater $C_{\mathrm{o}}$ conditions, and the mass fraction of NO is minimized at the carrier outlet at different $C_{\mathrm{o}}$ conditions. With the $C_{\mathrm{o}}$ increases from $1.2 \%$ to $2.0 \%$, the minimum NO mass fraction value is reduced from $368 \mathrm{ppm}$ to $264 \mathrm{ppm}$. This is mainly because when the $C_{\mathrm{o}}$ increases, the catalytic reaction rate of the exhaust gas is accelerated by the catalyst, resulting in a quicker catalytic reaction efficiency and a rapid decrease in the NO mass fraction. Thus, an appropriate increase in $C_{\mathrm{o}}$ is beneficial for increasing the NOx conversion efficiency. 

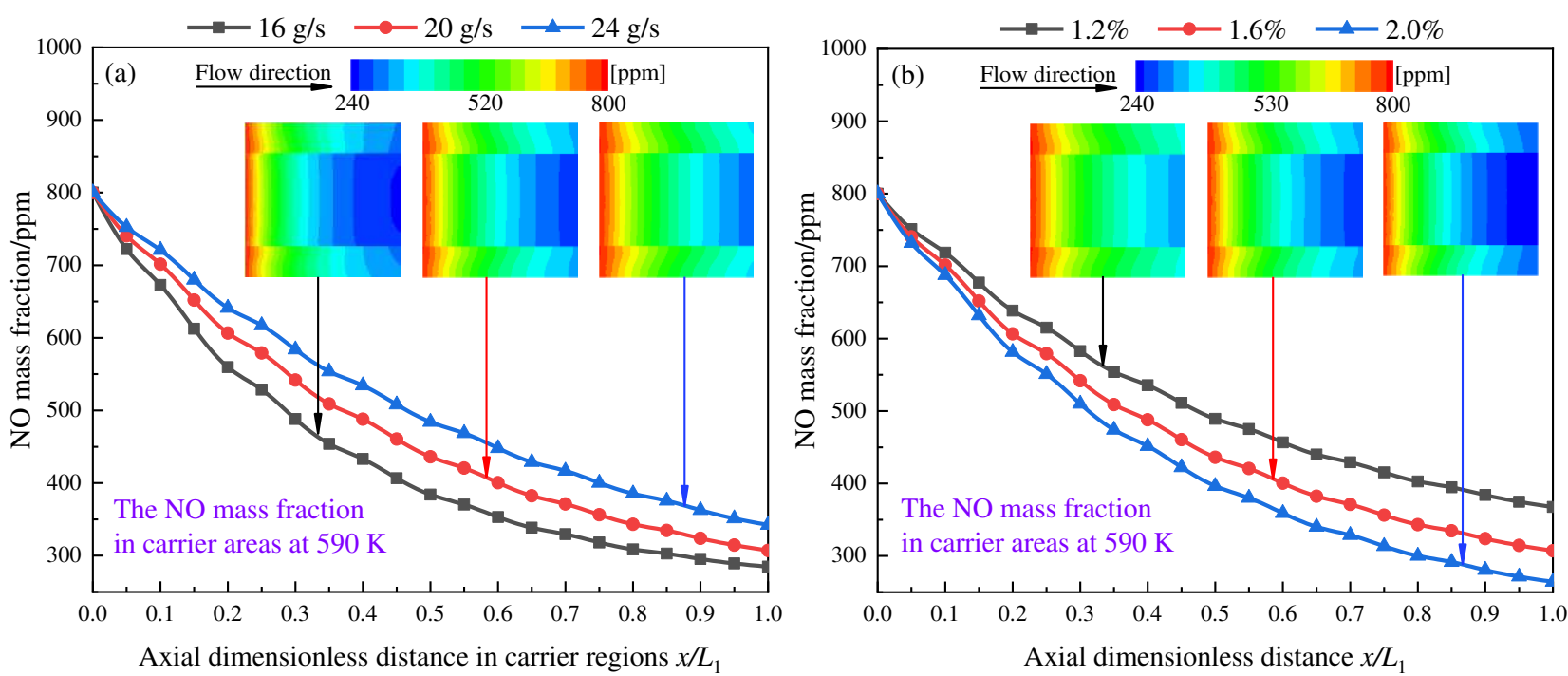

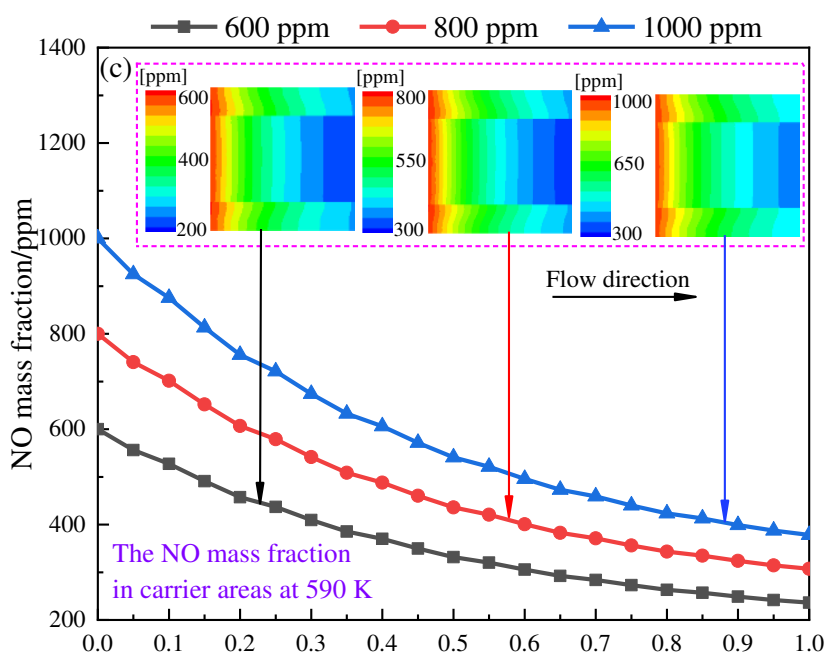

Axial dimensionless distance in carrier regions $x / L_{1}$

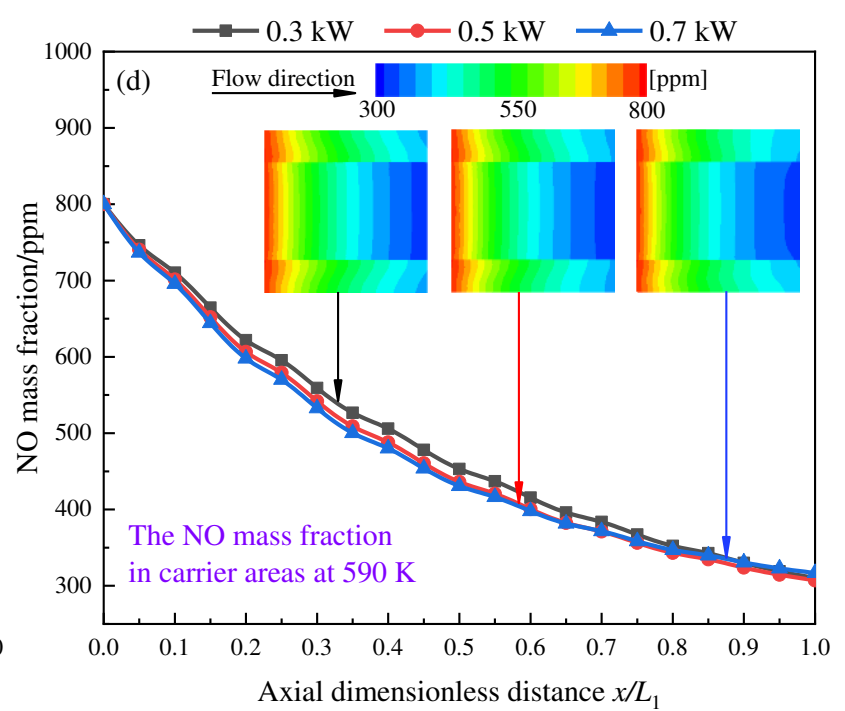

Fig. 10. The distribution pattern of NO mass fraction

As we can see from Fig. 10(c), the mass fraction of NO decreases gradually with increasing greater oxygen concentrations, and the mass fraction of NO is minimized at the carrier outlet at different $C_{\mathrm{NO}}$ conditions. As the $C_{\mathrm{NO}}$ increases from $600 \mathrm{ppm}$ to $1000 \mathrm{ppm}$, the minimum mass fraction value of NO is increased from $236 \mathrm{ppm}$ to $378 \mathrm{ppm}$. This is mainly because as the $C_{\mathrm{NO}}$ increases, the NO concentration increases correspondingly at the inlet of the carrier areas. Among the gasoline exhaust gases, since the catalytic efficiency of NO is almost the same for different $C_{\mathrm{NO}}$ 
conditions, the exhaust gas with higher NO concentration has a higher NO mass fraction at the same dimensionless distance. Thus, an appropriate increase in $C_{\mathrm{NO}}$ is beneficial for increasing the NOx conversion efficiency.

As we can see from Fig. 10(d), the mass fractions of NO decreases gradually with increasing dimensionless distance $x / L_{1}$ at various $P_{\mathrm{e}}$ conditions. The mass fraction of NO decreases faster at larger $P_{\mathrm{e}}$ conditions, and the mass fraction of NO is minimized at the carrier outlet under various $P_{\mathrm{e}}$ conditions. The minimum mass fraction values of NO are $310 \mathrm{ppm}, 307 \mathrm{ppm}$, and $317 \mathrm{ppm}$ at $0.3 \mathrm{~kW}, 0.5 \mathrm{~kW}$, and $0.7 \mathrm{~kW}$ of heating power, respectively. This is mainly because the NO catalytic reaction is almost complete at $0.3 \mathrm{~kW}$ of $P_{\mathrm{e}}$, and a further increase in heating power does not increase the catalytic efficiency of NO significantly. Therefore, the minimal mass fraction of NO varies less for different $P_{\mathrm{e}}$ conditions.

\section{Orthogonal experiment design and analysis}

\subsection{Experimental scheme design}

To use partial experiments instead of comprehensive experiments, the range analysis method of orthogonal experiment is used to analyze the primary and secondary effects of different factors

434 on the integrated t regeneration property of the novel CGPFs (Zuo et al. 2018; Zuo et al. 2019). The 435 influencing factors include the flow rate $v_{\mathrm{f}}$, oxygen concentration $C_{\mathrm{o}}$, NO concentration $C_{\mathrm{NO}}$ and 436 heating power $P_{\mathrm{e}}$. Table 7 shows the designed schemes of orthogonal experiment, which include 9 437 examples. 


\begin{tabular}{ccccc}
\hline Examples & $v_{\mathrm{f}}$ & $C_{\mathrm{o}}$ & $C_{\mathrm{NO}}$ & $P_{\mathrm{e}}$ \\
\hline 1 & $16 \mathrm{~g} / \mathrm{s}$ & $1.2 \%$ & $1000 \mathrm{ppm}$ & $0.3 \mathrm{~kW}$ \\
2 & $16 \mathrm{~g} / \mathrm{s}$ & $1.6 \%$ & $800 \mathrm{ppm}$ & $0.5 \mathrm{~kW}$ \\
3 & $16 \mathrm{~g} / \mathrm{s}$ & $2.0 \%$ & $600 \mathrm{ppm}$ & $0.7 \mathrm{~kW}$ \\
4 & $20 \mathrm{~g} / \mathrm{s}$ & $1.2 \%$ & $800 \mathrm{ppm}$ & $0.3 \mathrm{~kW}$ \\
5 & $20 \mathrm{~g} / \mathrm{s}$ & $1.6 \%$ & $600 \mathrm{ppm}$ & $0.5 \mathrm{~kW}$ \\
6 & $20 \mathrm{~g} / \mathrm{s}$ & $2.0 \%$ & $1000 \mathrm{ppm}$ & $0.5 \mathrm{~kW}$ \\
7 & $24 \mathrm{~g} / \mathrm{s}$ & $1.2 \%$ & $600 \mathrm{ppm}$ & $0.7 \mathrm{~kW}$ \\
9 & $24 \mathrm{~g} / \mathrm{s}$ & $1.6 \%$ & $1000 \mathrm{ppm}$ & $0.3 \mathrm{~kW}$ \\
\hline
\end{tabular}

\subsection{The results of orthogonal experiment}

443 NOx conversion efficiency and particulate combustion efficiency of the 9 examples are obtained.

444 Fig. 11 shows the simulation results of the 9 examples.

In Fig. 11(a), it is clearly seen that the average NOx conversion efficiency of the 9 examples is $44659.7 \%$. Compared with other examples, the NO catalytic efficiencies of examples 1, 4 and 7 are far 447 less than the average value, while those of examples 3,6 and 9 are far greater than the average 448 value. Combined with Table 7, it is found that the flow rate $v_{\mathrm{f}}$ is the key factor affecting the NOx 449 conversion efficiency. 


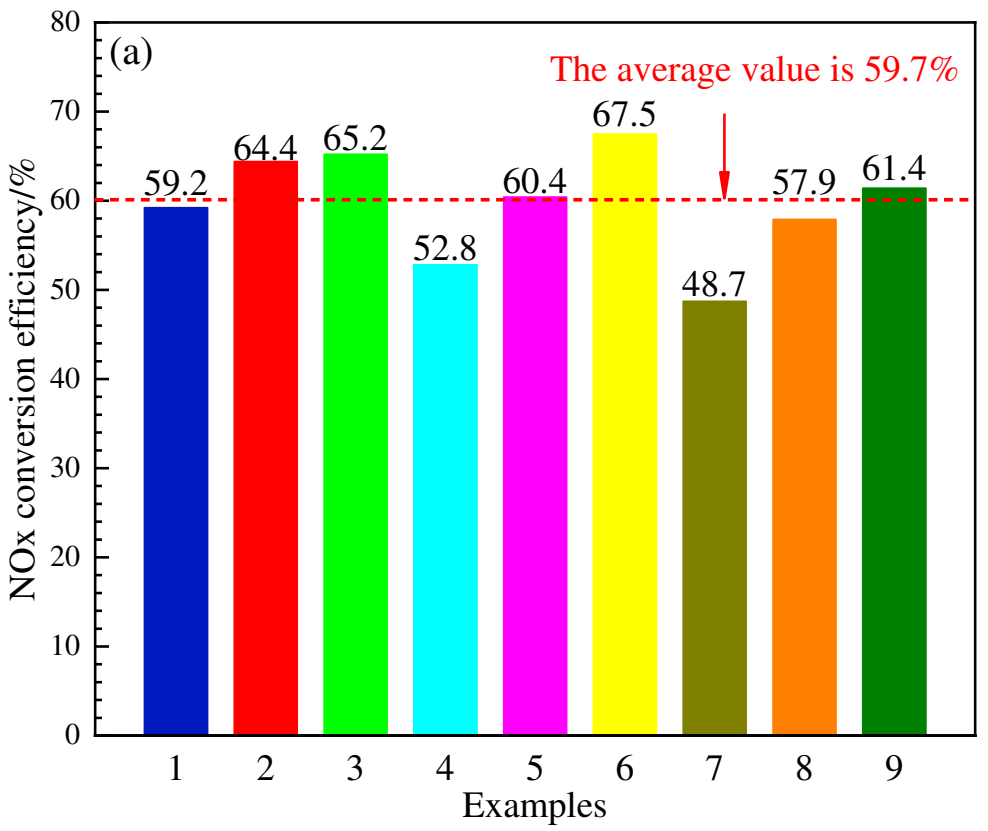

(a) NOx conversion efficiency

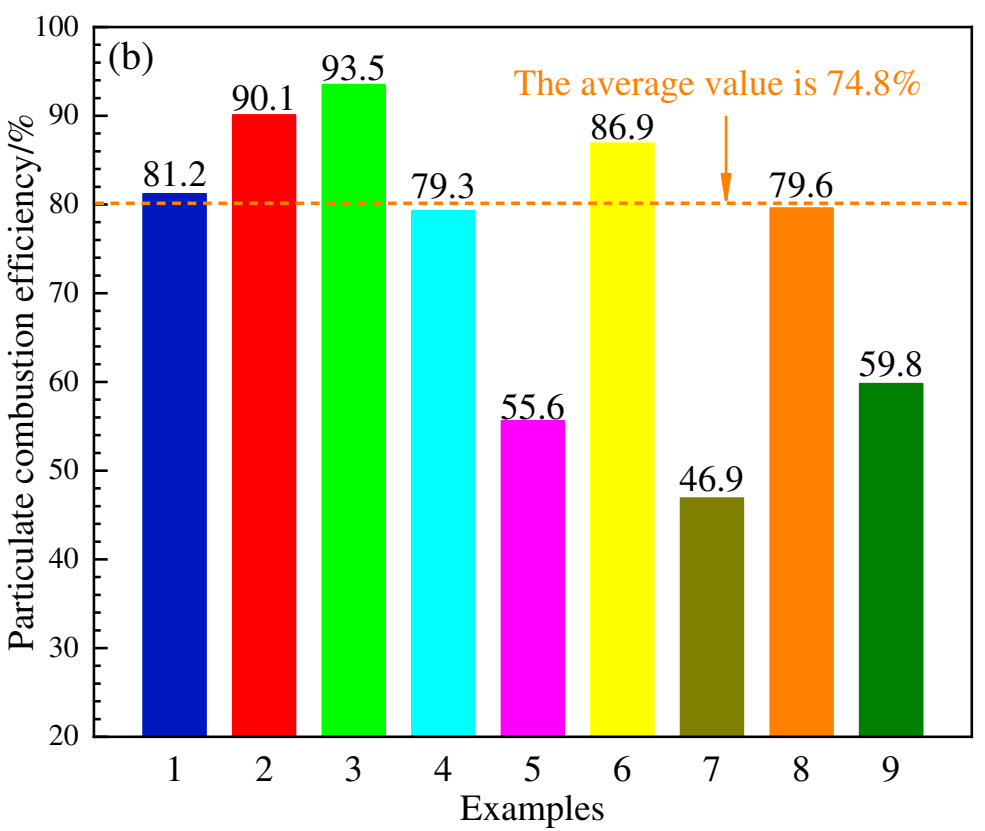

(b) Particulate combustion efficiency

454 Fig. 11. Orthogonal experiment results of NOx conversion efficiency and particulate combustion efficiency

455 In Fig. 11(b), it is clearly seen that the average particulate combustion efficiency of the 9 456 examples is $74.8 \%$. Compared with other examples, the particulate oxidation efficiencies of 457 examples 7, 8 and 9 are far less than the average value, while those of examples 1, 2 and 3 are far 

greater than the average value. Combined with Table 7, it is found that the oxygen concentration $C_{\mathrm{o}}$ is the key factor affecting the particulate combustion efficiency. affecting the NOx conversion efficiency and particulate combustion efficiency is calculated through the range analysis method (Lin et al. 2019), as shown in Fig. 12. As we can see from the figure, the range percentages of $v_{\mathrm{f}}, C_{\mathrm{o}}, C_{\mathrm{NO}}$, and $P_{\mathrm{e}}$ on NOx conversion efficiency are $29.9 \% 、 48 \% 、 14.8 \%$, and $7.3 \%$, respectively. The range percentages of particulate combustion efficiency are $35.9 \%$ 、 $15 \%$ 、 $23.6 \%$, and $25.5 \%$, respectively. Therefore, the primary and secondary effect of each factor on the catalytic efficiency of NO is $C_{\mathrm{o}}>v_{\mathrm{f}}>C_{\mathrm{NO}}>P_{\mathrm{e}}$. The primary and secondary effect of each factor on the particulate combustion efficiency is $v_{\mathrm{f}}>C_{\mathrm{o}}>C_{\mathrm{NO}}>P_{\mathrm{e}}$.

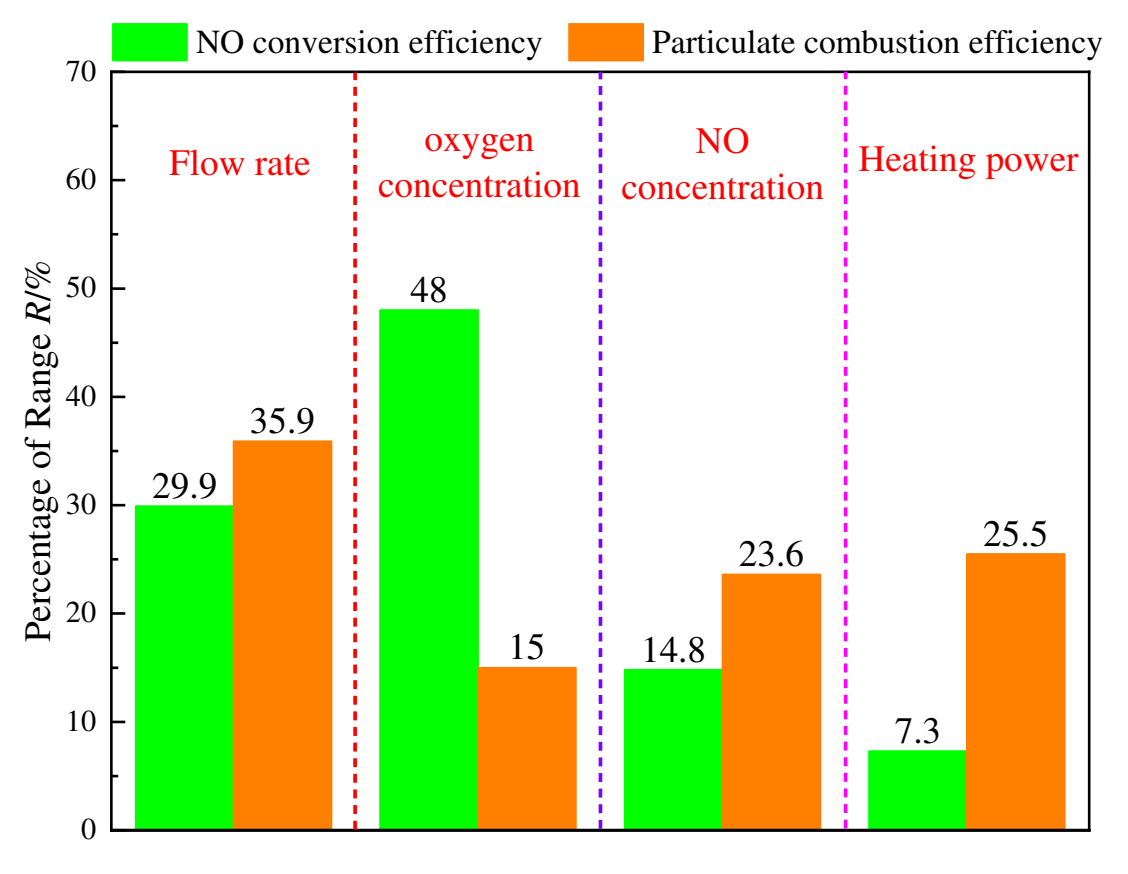

\subsection{Optimal results}

Fig.12. Range percentage of each influencing factor

As we can see from Fig. 13, the novel CGPFs can reach a high catalytic efficiency of NO and combustion efficiency of particulate when the $v_{\mathrm{f}}$ is $16 \mathrm{~g} / \mathrm{s}$, the $C_{\mathrm{o}}$ is $2.0 \%$, the $C_{\mathrm{NO}}$ is $600 \mathrm{ppm}$, and 

of particulate is increased by $16.7 \%$ with a $0.2 \mathrm{~kW}$ increase in electric heating power compared to the initial condition.

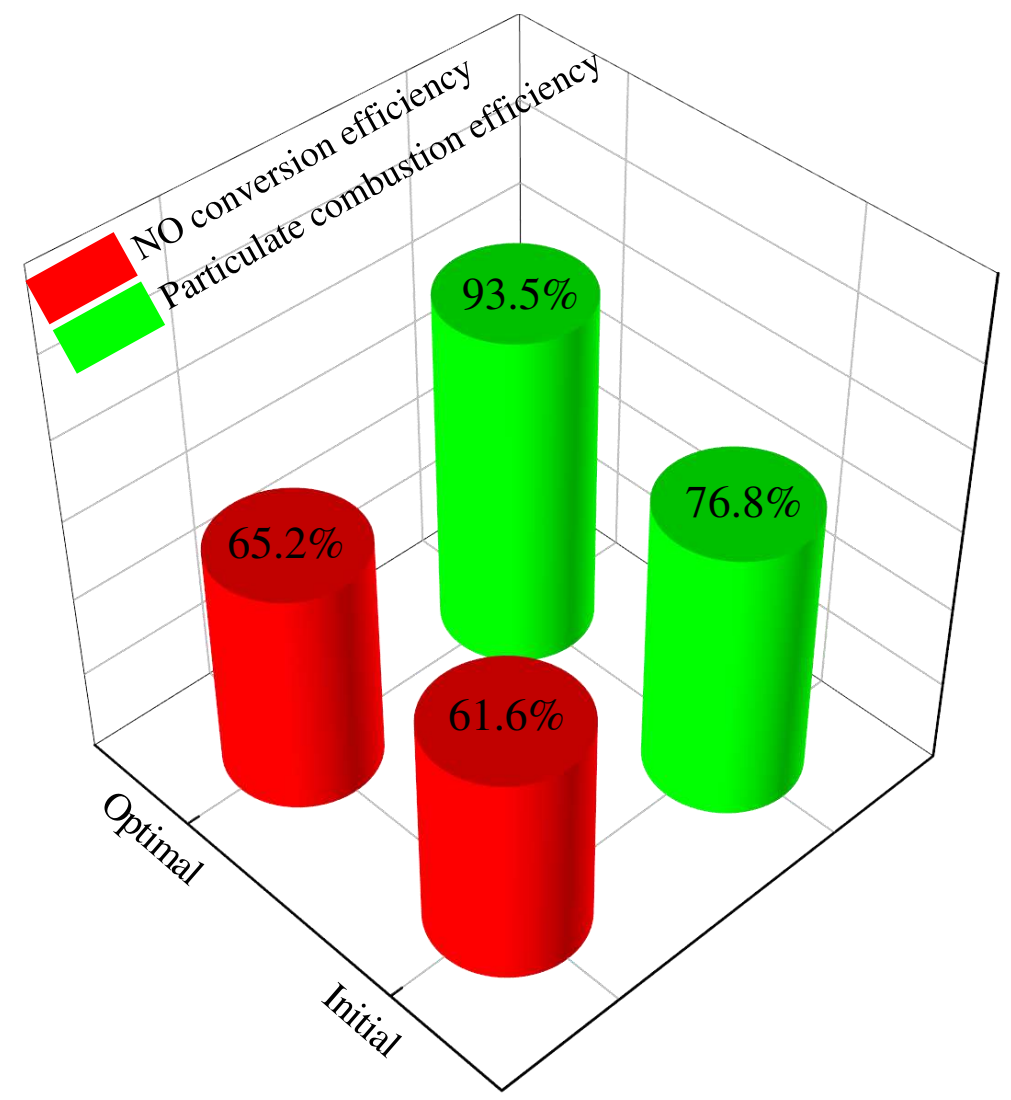

Fig. 13. Comparison of optimal results.

\section{Conclusions}


conversion efficiency and particulate combustion efficiency at low exhaust temperature conditions, the physical and mathematical models of a novel CGPFs are proposed based on the computational fluid dynamics software. The influence patterns of different influencing factors on the NOx conversion efficiency and particulate combustion efficiency of CGPFs are investigated. The main findings are as follows:

(1) Properly reducing the flow rate $v_{\mathrm{f}}$ is conducive to improving the NOx conversion efficiency and particulate combustion efficiency. The maximal catalytic efficiency of $\mathrm{NO}$ is enhanced from $57 \%$ to $66 \%$ as the $v_{\mathrm{f}}$ decreases from $24 \mathrm{~g} / \mathrm{s}$ to $16 \mathrm{~g} / \mathrm{s}$. The NO mass fraction at the carrier outlet is reduced from $342 \mathrm{ppm}$ to $285 \mathrm{ppm}$ when the $v_{\mathrm{f}}$ reduces from $24 \mathrm{~g} / \mathrm{s}$ to $16 \mathrm{~g} / \mathrm{s}$.

(2) Properly increasing the oxygen concentration $C_{\mathrm{o}}$ is conducive to improving the NOx conversion efficiency and particulate combustion efficiency. The maximal catalytic efficiency of NO is enhanced from $54 \%$ to $67 \%$ with the $C_{\mathrm{o}}$ increases from $1.2 \%$ to $2.0 \%$. The NO mass fraction at the carrier outlet decreases from $368 \mathrm{ppm}$ to $264 \mathrm{ppm}$ when the $C_{\mathrm{o}}$ increases from $1.2 \%$ to $2.0 \%$.

(3) Properly increasing the NO concentration $C_{\mathrm{NO}}$ is conducive to improving the NOx conversion efficiency and particulate combustion efficiency. The maximal catalytic efficiency of NO is enhanced from $60.7 \%$ to $62.2 \%$ with the $C_{\text {NO }}$ increases from $600 \mathrm{ppm}$ to $1000 \mathrm{ppm}$. The minimal mass fraction value of NO is increased from $236 \mathrm{ppm}$ to $378 \mathrm{ppm}$ while the $C_{\mathrm{NO}}$ increases from 600 ppm to 1000 ppm.

(4) Properly increasing the heating power $P_{\mathrm{e}}$ is conducive to improving the NOx conversion efficiency and particulate combustion efficiency. The maximal catalytic efficiency of NO is maintained at $62 \%$ as the $P_{\mathrm{e}}$ increases from $0.3 \mathrm{~kW}$ to $0.7 \mathrm{~kW}$. The combustion efficiency of 
particulate is higher while the $P_{\mathrm{e}}$ is greater at identical exhaust temperatures.

506 (5) The novel CGPFs can reach a high catalytic efficiency of NO and combustion efficiency of 507 particulate when the $v_{\mathrm{f}}$ is $16 \mathrm{~g} / \mathrm{s}$, the $C_{\mathrm{o}}$ is $2.0 \%$, the $C_{\mathrm{NO}}$ is $600 \mathrm{ppm}$, and the $P_{\mathrm{e}}$ is $0.7 \mathrm{~kW}$. The 508 catalytic efficiency of NO is increased by $3.6 \%$ and the combustion efficiency of particulate is 509 increased by $16.7 \%$ with a $0.2 \mathrm{~kW}$ increase in electric heating power compared to the initial 510 condition.

\section{Authors' contributions}

512 Yong Xie: Software, Data curation, Writing-Original Draft, Formal analysis. Qingsong Zuo: 513 Resources, Funding acquisition, Project administration, Data curation, Writing-Original Draft. 514 Qingwu Guan: Data curation. Kexiang Wei: Conceptualization, Methodology. Bin Zhang: Formal 515 analysis.

\section{Funding}

This work is supported by the National Natural Science Foundation of China (Grant No. 518 52076184), the Natural Science Foundation of Hunan Province (Grant No. 2020JJ6002), the Hunan 519 Provincial Key Laboratory of Vehicle Power and Transmission System (Grant No. VPTS202004).

\section{Data availability}

521 The present study data are available from the corresponding author on reasonable request.

\section{Competing interests}

523 The authors declare that they have no competing interests.

\section{Availability of data and materials}

525 All data generated or analyzed during this study are included in this published article. 
Ethical approval and consent to participate

This article does not contain any studies with human participants or animals.

\section{Consent for publication}

529

Not applicable.

\section{References}

Arunachalam H, Pozzato G, Hoffman MA, Onori S. (2020) Modeling the thermal and soot oxidation dynamics inside a ceria-coated gasoline particulate filter. Control Eng Pract 94.104199. 10.1016/j.conengprac.2019.104199.

Bermudez V, Serrano JR, Piqueras P, Garcia-Afonso O. (2015) Pre-DPF water injection technique for pressure drop control in loaded wall-flow diesel particulate filters. Appl Energ 140:234-245. https://doi.org/10.1016/j.apenergy.2014.12.003

Bock NRH, Baum MM, Moss JA, Castonguay AE, Jocic S, Northrop WF. (2020) Dicarboxylic acid emissions from a GDI engine equipped with a catalytic gasoline particulate filter. Fuel 275.https://doi.org/10.1016/j.fuel.2020.117940.

Broatch A, José ML, José RS, Pla BJ. (2008) A procedure to reduce pollutant gases from Diesel combustion during European MVEG-A cycle by using electrical intake air-heaters. Fuel 87(12):2760-2778. https://doi.org/10.1016/j.ffue.2008.01.026.

Chen CY, Lee WJ, Wang LC, Chang YC, Yang HH, Young LH, Lu JH, Tsai YI, Cheng MT, Mwangi JK. (2017) Impact of high soot-loaded and regenerated diesel particulate filters on the emissions of persistent organic pollutants from a diesel engine fueled with waste cooking oil-based biodiesel. Appl Energ 191:35-43. https://doi.org/10.1016/j.apenergy.2017.01.046. 
547 Chen PE, Wang JM. (2014) Air-fraction modeling for simultaneous Diesel engine NOx and PM 548 emissions control during active DPF regenerations. Appl Energ 122:310-320. $549 \quad$ https://doi.org/10.1016/j.apenergy.2014.02.031.

550 Caliskan H, Mori K. (2017) Environmental, enviroeconomic and enhanced thermodynamic analyses 551 treatment systems. Energy 128:128-144. https://doi.org/10.1016/j.energy.2017.04.014.

553 Choi S, Oh KC, Lee CB. (2014) The effects of filter porosity and flow conditions on soot deposition/oxidation and pressure drop in particulate filters. Energy 77: 327-337.

Dai CH, Huang SJ, Zhou YY, Xu B, Peng H, Qin PF, Wu GY. (2019) Concentrations and emissions of particulate matter and ammonia from extensive livestock farm in South China. Environ Sci Pollut Res 26: 1871-1879. https://doi.org/10.1007/s11356-018-3766-4.

Distaso E, Amirante R, Tamburrano P, Reitz RD. (2019) Understanding the role of soot oxidation in gasoline combustion: A numerical study on the effects of oxygen enrichment on particulate mass and number emissions in a spark-ignition engine. Energ Convers Manage 184: 24-39. https://doi.org/10.1016/j.enconman.2019.01.022

Du JK, Sun WC, Guo L, Xiao SL, Tan MZ, Li GL, Fan LY. (2015) Experimental study on fuel economies and emissions of direct-injection premixed combustion engine fueled with gasoline/diesel blends. Energ Convers and Manage 100: 300-309. https://doi.org/10.1016/j.enconman.2015.04.076.

Dey S, Chandra DG. (2020) Controlling carbon monoxide emissions from automobile vehicle 
exhaust using copper oxide catalysts in a catalytic converter. Mater $\mathrm{T}$ oday Chem 17: https://doi.org/10.1016/j.mtchem.2020.100282.

Deng YW, Zheng WP, E JQ, Zhang B, Zhao XH, Zuo QS, Zhang ZQ, Han DD. (2017) Influence of geometric characteristics of a diesel particulate filter on its behavior in equilibrium state. Appl Therm Eng 123:61-73. https://doi.org/10.1016/j.applthermaleng.2017.05.071.

E JQ, Zhao MY, Zuo QS, Zhang B, Zhang ZQ, Peng QG, Han DD, Zhao XH, Deng YW. (2020a) Effects analysis on diesel soot continuous regeneration property of a rotary microwave-assisted regeneration diesel particulate filter. Fuel 260: https://doi.org/10.1016/j.fuel.2019.116353.

E JQ, Zhao XH, Liu HL, Chen JM, Zuo W, Peng QG. (2016) Field synergy analysis for enhancing heat transfer capability of a novel narrow-tube closed oscillating heat pipe. Appl Energ 175:218-228. https://doi.org/10.1016/j.apenergy.2016.05.028.

E JQ, Zheng PY, Han DD, Zhao XH, Deng YW. (2020b) Effects analysis on soot combustion property enhancement in a rotary diesel particulate filter unit during continuous microwave heating. Fuel 276: https://doi.org/10.1016/j.fuel.2020.118043.

Fang J, Meng ZW, Li JS, Du YH, Qin Y, Jiang Y, Bai WL, Chase GG. (2019) The effect of operating parameters on regeneration characteristics and particulate emission characteristics of diesel $\begin{array}{lllll}\text { particulate } & \text { filters. } & \text { Appl } & \text { Therm }\end{array}$ https://doi.org/10.1016/j.applthermaleng.2018.11.066.

Horng RF. Chou HM. (2004) Effect of input energy on the emission of a motorcycle engine with an electrically heated catalyst in cold-start conditions. Appl Therm Eng 24:2017-2028. https://doi.org/10.1016/j.applthermaleng.2004.02.005. 
Ibrahim HA, Ahmed WH, Abdou S, Blagojevic V. (2018) Experimental and numerical investigations of flow through catalytic converters. Int J Heat Mass Tran 127:546-560. https://doi.org/10.1016/j.ijheatmasstransfer.2018.07.052.

Jain A, Singh AP, Agarwal AK. (2017) Effect of split fuel injection and EGR on NOx and PM emission reduction in a low temperature combustion (LTC) mode diesel engine. Energy 122:249-264. https://doi.org/10.1016/j.energy.2017.01.050.

Jiang X, Deng FQ, Yang FY, Zhang YJ, Huang ZH. (2017) High temperature ignition delay time of DME/n-pentane mixture under fuel lean condition. Fuel 191:77-86. https://doi.org/10.1016/j.fuel.2016.11.061.

Jiao PH, Li ZJ, Shen BX, Zhang W, Kong XJ, Jiang R. (2017) Research of DPF regeneration with NOx-PM coupled chemical reaction. Appl Therm Eng 110:737-745. https://doi.org/10.1016/j.applthermaleng.2016.08.184.

Ko J, Kim K, Chung W, Myung CL, Park S. (2019) Characteristics of on-road particle number (PN) emissions from a GDI vehicle depending on a catalytic stripper (CS) and a metal-foam gasoline particulate filter (GPF). Fuel 238:363-374. https://doi.org/10.1016/j.fuel.2018.10.091.

Lin R, Diao X Y, Ma T C, Tang SH, Chen L, Liu DC. (2019) Optimized microporous layer for improving polymer exchange membrane fuel cell performance using orthogonal test design. Appl Energ 254: https://doi.org/10.1016/j.apenergy.2019.113714.

Mianzarasvand F, Shirneshan A, Afrand M. (2017) Effect of electrically heated catalytic converter on emission characteristic of a motorcycle engine in cold-start conditions: CFD simulation and kinetic study. Appl Therm Eng $127: 453-464$. 

https://doi.org/10.1016/j.applthermaleng.2017.07.180.

611 Mu M, Li X, Qiu Y, Shi Y. (2019) Study on a new gasoline particulate filter structure based on the nested cylinder and diversion channel plug. Energies 12(11): https://doi.org/10.3390/en12112045.

Markides CN, Paola GD, Mastorakos E. (2007) Measurements and simulations of mixing and autoignition of an n-heptane plume in a turbulent flow of heated air. Exp Therm Fluid Sci 31(5): 393-401. https://doi.org/10.1016/j.expthermflusci.2006.04.008

Pan MZ, Bian XY, Zhu Y, Liang YC, Lu FL, Xiao G. (2020) Thermodynamic analysis of a combined supercritical $\mathrm{CO}_{2}$ and ejector expansion refrigeration cycle for engine waste heat recovery. Energ Convers Manage 224: https://doi.org/10.1016/j.enconman.2020.113373.

Pantaleo AM, Simpson M, Rotolo G, Distaso E, Oyewunmi OA, Sapin P, Palma PD, Markides CN. (2019) Thermoeconomic optimisation of small-scale organic Rankine cycle systems based on screw vs. piston expander maps in waste heat recovery applications. Energ Convers Manage 200:112053. https://doi.org/10.1016/j.enconman.2019.112053.

Qian Y, Li Z, Yu L, Wang X, Lu X. (2019) Review of the state-of-the-art of particulate matter impacts. Environ Sci Pollut Res 26: 35082-35093. 
631 Vaishnav SS, Vignesh V. (2014) A computational flow analysis for optimising the inlet diffuser

632 633 634 635 636 637 638 639 640 design in automotive catalytic converter. Int J Eng Res T echnol 3:1451-1463.

Wang HH, Ge YS, Tan JW, Hao LJ, Peng ZH, Wang X, Wu LG, Li YH, Yang J, Li JC, Yang DX. (2018) The effects of ash inside a platinum-based catalyst diesel particulate filter on particle emissions, gaseous emissions, and unregulated emissions. Environ Sci Pollut Res 25: 33736-33744. https://doi.org/10.1007/s11356-018-3328-9.

Wang HH, Tan JW, Ge YS, Li JC, Yan XD, Wang CJ, Lv LQ, Tan D, Tian WD, Wang YL, Hao LJ. (2020) Pore morphology and fractal dimension of ash deposited in catalyst diesel particulate filter. Environ Sci Pollut Res 27: 11026-11037. https://doi.org/10.1007/s11356-019-06945-7.

White MT, Oyewunmi OA, Chatzopoulou MA, Pantaleo AM, Haslam AJ, Markides CN. (2018) Computer-aided working-fluid design, thermodynamic optimisation and thermoeconomic assessment of ORC systems for waste-heat recovery. Energy 161:1181-1198. https://doi.org/10.1016/j.energy.2018.07.098.

Xu L, Bai X, Li Y, Treacy M, Li C, Tunestal P, Tuner M, Lu XC. (2020) Effect of piston bowl geometry and compression ratio on in-cylinder combustion and engine performance in a gasoline direct-injection compression ignition engine under different injection conditions. Applied Energy 280:115920. https://doi.org/10.1016/j.apenergy.2020.115920.

Zhong WJ, Xuan TM, He ZX, Wang Q, Li D, Zhang X, Huang YY. (2016) Experimental study of combustion and emission characteristics of diesel engine with diesel/second-generatiosn biodiesel blending fuels. Energ Convers and Manage 121:241-250. https://doi.org/10.1016/j.enconman.2016.05.033. 
Zuo QS, Tang YY, Zhu GH, Wei KX, Guan QW, Zhang B, Shen Z. (2021) Investigations on the soot combustion performance enhancement of a catalytic gasoline particulate filter in equilibrium state for reducing the BSFC of gasoline direct injection engine. Fuel 284. https://doi.org/10.1016/j.fuel.2020.119032.

Zhong C, Gong JK, Wang SL, Tan JQ, Liu JN, Zhu Y, Jia GH. (2021) $\mathrm{NO}_{2}$ catalytic formation, consumption, and efflux in various types of diesel particulate filter. Environ Sci Pollut Res 28: 20034-20044. https://doi.org/10.1007/s11356-020-11870-1.

Zhang B, E JQ, Gong JK, Deng YW, Zuo W, Li Y, Fu J. (2016) Multidisciplinary design optimization of the diesel particulate filter in the composite regeneration process. Appl Energ 181:14-28. https://doi.org/10.1016/j.apenergy.2016.08.051.

Zhang J, Wong VW, Shuai SJ, Chen Y, Sappok A. (2018) Quantitative estimation of the impact of ash accumulation on diesel particulate filter related fuel penalty for a typical modern on-road heavy-duty diesel engine. Appl Energ 229:1010-1023. https://doi.org/10.1016/j.apenergy.2018.08.071.

Zhong C, Gong JK, Liu WQ, Liu GL. (2019) Low temperature, medium temperature and high temperature property of the continuous regenerative diesel particulate filter assisted by electric regeneration. Chem Eng Sci 207:980-992. https://doi.org/10.1016/j.ces.2019.07.024.

Zhao LL, Ou XM, Chang SY. (2016) Life-cycle greenhouse gas emission and energy use of bioethanol produced from corn stover in China: Current perspectives and future prospectives. Energy 115(1): 303-313. https://doi.org/10.1016/j.energy.2016.08.046.

Zhao XH, E JQ, Liao GL, Zhang F, Chen JW, Deng YW. (2020) Numerical simulation study on 
soot continuous regeneration combustion model of diesel particulate filter under exhaust gas heavy load. Fuel 290:119795. https://doi.org/10.1016/j.fuel.2020.119795.

675 Zhang B, E JQ, Gong JK, Yuan WH, Zhao XH, Hu WY. (2017) Influence of structural and 676

677 composite regeneration.

Appl

Therm

Eng

121:838-852.

678 https://doi.org/10.1016/j.applthermaleng.2017.04.155.

679 Zuo W, E JQ, Lin RM. (2018) Numerical investigations on an improved counterflow 680 double-channel micro combustor fueled with hydrogen for enhancing thermal performance. 681 Energ Convers Manage 159:163-174. https://doi.org/10.1016/j.enconman.2018.01.017.

682 Zuo QS, Zhu XN, Zhang JP, Zhang B, Tang YY, Xie Y, Zhang XT, Zhu GH, Wang ZQ. (2019) 683 Effects of exhaust parameters on temperature and pressure drop of the gasoline particulate 684 filter in the regeneration equilibrium state.

Fuel 257. https://doi.org/10.1016/j.fuel.2019.116019. 